\title{
Potassium Current Development and its Linkage to Membrane Expansion During Growth of Cultured Embryonic Mouse Hippocampal Neurons: Sensitivity to Inhibitors of Phosphatidylinositol 3-Kinase and Other Protein Kinases
}

\author{
Rui-Lin Wu, Donna M. Butler, and Michael E. Barish \\ Division of Neurosciences, Beckman Research Institute of the City of Hope, Duarte, California 91010
}

Hippocampal pyramidal neurons express three major voltagedependent potassium currents, $I_{\mathrm{A}}, I_{\mathrm{D}}$, and $I_{\mathrm{K}}$. During hippocampal development, $I_{\mathrm{A}}$, the rapidly activating and inactivating transient potassium current, is detected soon after pyramidal neurons can be morphologically identified. Appearance of $I_{\mathrm{A}}$ in developing pyramidal neurons is dependent on contact with cocultured astroglial cells; cultured pyramidal neurons not in contact with astroglial cells have reduced membrane area and $I_{\mathrm{A}}$ (Wu and Barish, 1994).

We have examined intracellular signaling pathways that could contribute to the regulation of $I_{A}$ development by probing developing pyramidal neurons with kinase inhibitors. We observed that exposure to LY294002 or wortmannin, inhibitors of phosphatidylinositol (PI) 3-kinase, reduced somatic crosssectional area, neurite outgrowth, whole-cell capacitance, $I_{\text {A }}$ amplitude and density (amplitude normalized to membrane area), and immunoreactivity for Kv4.2 and/or Kv4.3 (potassium channel subunits likely to be present in the channels carrying $\left.I_{\mathrm{A}}\right)$. In contrast, exposure to ML-9 or $\mathrm{KN}-62$, inhibitors of myosin light chain kinase or $\mathrm{Ca}^{2+}$-calmodulin-dependent protein kinase II (CaMKII), reduced membrane area and $I_{\mathrm{A}}$ amplitude but did not affect $I_{A}$ density or Kv4.2/3 immunoreactivity to the same extent as inhibitors of PI 3-kinase. Unexpectedly, exposure to bisindolymaleimide I or calphostin C, inhibitors of protein kinase $\mathrm{C}(\mathrm{PKC})$, did not affect membrane area or potassium current development.

Our data suggest that PI 3-kinases regulate both A-type potassium channel synthesis and plasmalemmal insertion of vesicles bearing these potassium channels. CaMKII appears to regulate fusion of channel-bearing vesicles with the plasmalemma and myosin light chain kinase to regulate centripetal transport of channel-bearing vesicles from the Golgi. We further suggest that astroglial cells exert their influence on pyramidal neuron development through activation of PI 3-kinases.

Key words: hippocampus; development; excitability; potassium channels; $\mathrm{I}_{A} ; \mathrm{I}_{D} ; \mathrm{I}_{K} ;$ membrane expansion; neurite outgrowth; phosphatidylinositol 3-kinase; calcium-calmodulindependent protein kinase II; myosin light chain kinase
Hippocampal pyramidal neurons display three major voltagedependent potassium currents (Storm, 1990), $I_{\mathrm{A}}, I_{\mathrm{D}}$, and $I_{\mathrm{K}} \cdot I_{\mathrm{A}}$ is a rapidly activating and inactivating voltage-gated potassium current that influences the subthreshold electrical behavior of neurons (Connor and Stevens, 1971a,b). It is a particularly important regulator of postsynaptic efficacy and dendritic excitability in pyramidal neurons (Hoffman et al., 1997). Physiological evidence suggests that the Shal-related potassium channel subunits Kv4.2 and/or Kv4.3 (Serôdio et al., 1996; Tsaur et al., 1997) are likely to be components of the dendritic potassium channels carrying $I_{\mathrm{A}}$ in hippocampal neurons (Serôdio et al., 1994; Keros and McBain, 1997; Johns et al., 1997), and immunocytochemical evidence indicates that Kv4.2 and/or Kv4.3 protein is localized to the somatic and dendritic compartments of hippocampal pyramidal neurons (Sheng et al., 1992; Maletic-Savatic et al., 1995b; Tsaur et al., 1997; see below). Control of the insertion of these channels

\footnotetext{
Received Feb. 18, 1998; revised June 1, 1998; accepted June 9, 1998.

This work was supported by National Institutes of Health National Institute of Neurological Diseases and Stroke Grant R01 NS23857. We thank Arlene Y. Chiu and Charles E. Niesen for their helpful comments on this manuscript, Dianne M. Barry and Jeanne M. Nerbonne for their generous gifts of antibodies, and M. Jill Flanagan for her assistance with manuscript preparation.

Correspondence should be addressed to Dr. Michael E. Barish, Division of Neurosciences, Beckman Research Institute of the City of Hope, Duarte, CA 91010. Copyright (C) 1998 Society for Neuroscience $0270-6474 / 98 / 186261-18 \$ 05.00 / 0$
}

into dendritic membrane is thus critical for tuning the integrative properties of pyramidal neuron dendrites.

$I_{\mathrm{A}}$ is detected early in the development of hippocampal pyramidal neurons, and $I_{\mathrm{A}}$ amplitude increases rapidly during the late embryonic-early postnatal developmental period (Ficker and Heinemann, 1992; Spigelman et al., 1992; Wu and Barish, 1992). One factor influencing the development of $I_{\mathrm{A}}$ in pyramidal neurons in dissociated cell culture is contact of individual neurons with cocultured astroglial cells (Wu and Barish, 1994; see also Barish, 1995). Pyramidal neurons in contact with astroglial cells have greater membrane area and a prominent $I_{\mathrm{A}}$; pyramidal neurons not in contact with astroglial cells have reduced membrane area and are deficient in $I_{\mathrm{A}}$. This $I_{\mathrm{A}}$ deficit is seen in both $I_{\mathrm{A}}$ amplitude and in $I_{\mathrm{A}}$ density (amplitude normalized to membrane area). We have suggested that glial-derived signals, transmitted by cell-cell contact or short-range diffusion, promote insertion of surface membrane enriched in A-type potassium channels. We have hypothesized, therefore, that astroglial contact is promoting two parallel processes: (1) membrane expansion and neurite outgrowth and (2) synthesis, transport, and/or insertion of A-type potassium channels into areas of expanding plasmalemma.

In the present experiments we have examined second messenger systems that may regulate $I_{\mathrm{A}}$ development by using selective inhibitors to probe kinases implicated in receptor signaling, 
and/or control of membrane trafficking and exocytosis: (1) phosphatidylinositol (PI) 3-kinase, (2) myosin light chain kinase, (3) $\mathrm{Ca}^{2+}$-calmodulin-dependent protein kinase II (CaMKII), and (4) protein kinase $\mathrm{C}$ (PKC), as well as (5) multiple kinases (using less selective kinase inhibitors). We made measurements of membrane area, amplitudes and densities of the three voltage-gated potassium currents, and in some particularly interesting cases, the subcellular distributions of Kv4.2 and/or Kv4.3 potassium channel subunits.

Our results indicate that in developing hippocampal pyramidal neurons PI 3-kinases have a central role in regulating synthesis of the channels carrying $I_{\mathrm{A}}$ and in regulating insertion of vesicles bearing these and other potassium channels into the expanding plasmalemma. Our data also indicate that CaMKII regulates fusion of channel-bearing vesicles with the plasmalemma, and that myosin light chain kinase influences centripetal transport of channel-bearing vesicles from the Golgi. We further suggest that PI 3-kinases may mediate the effects of astroglial cells on dendritic growth and $I_{\mathrm{A}}$ development.

Some of these results have previously been published in abstract form (Wu and Barish, 1996).

\section{MATERIALS AND METHODS}

Dissociated cell culture. Embryonic Swiss Webster mice were removed under sterile conditions from pregnant female mice after anesthesia (by halothane inhalation) and cervical dislocation, using procedures meeting National Institutes of Health guidelines. Hippocampi were removed from fetuses and dissociated using papain (Worthington, Freehold, NJ), as described in Wu and Barish (1992). Dissociated cells were plated at $\sim 22,100$ cells $/ \mathrm{cm}^{2}$ (25,000 cells per coverslip) onto poly-D-lysine-coated and laminin-coated $12 \mathrm{~mm}$-diameter glass coverslips (Assistent; Carolina Biological, Burlington, NC) in a $150 \mu \mathrm{l}$ bubble of medium (described below) supplemented to $10 \%$ total serum. After allowing $2 \mathrm{hr}$ for the cells to settle, each $35 \mathrm{~mm}$-diameter Petri dish containing three coverslips was flooded with $1 \mathrm{ml}$ of low-serum ( $2 \%$ total) medium.

Low-serum medium, which facilitates growth of neurons on a sparse underlying layer of astroglial cells, consisted of MEM supplemented with $1 \mathrm{~mm}$ glutamine, B-27 additive (1:50; Brewer et al., 1993), 1\% fetal bovine serum, and $1 \%$ horse serum, with total glucose increased to 25 $\mathrm{mm}$. No antibiotics were used, and an antimitotic, ara-C (10 $\mu \mathrm{M})$, was added after $12-48 \mathrm{hr}$ to control astroglial proliferation as desired. All components of tissue culture media, including sera and B-27, were purchased from Life Technologies (Gaithersburg, MD).

Electrophysiology. Procedures for whole-cell voltage clamp of voltagegated potassium current were standard and described in previous publications (Wu and Barish, 1992, 1994). The internal and external solutions were designed to minimize contributions of currents other than the three voltage-gated potassium currents under consideration.

Whole-cell recordings were made using an Axopatch 1B (Axon Instruments, Foster City, CA) amplifier modified for phase lag series resistance compensation and a TL-1/pClamp6 (Axon Instruments) data acquisition and analysis system. Currents were filtered in the Axopatch amplifier at $1 \mathrm{kHz}$ (-3 db; 4-pole Bessel filter). Currents linear with membrane voltage (leak currents and residual capacity transients) were subtracted using a $\mathrm{P} /-4$ voltage step protocol. Voltages were corrected for junction potentials between electrode and bath solutions, and series resistance was corrected at the amplifier to $\sim 80 \%$. Recordings were made at room temperature $\left(22-24^{\circ} \mathrm{C}\right)$.

The external solution was based on HBSS and contained (in mM): 140 $\mathrm{NaCl}, 5.8 \mathrm{KCl}, 1.8 \mathrm{CaCl}_{2}, 1 \mathrm{MgCl}_{2}, 4.2 \mathrm{NaHCO}_{3}, 5.5$ glucose, and 15 HEPES, pH 7.3. The normal internal solution contained (in mM): $59 \mathrm{KF}$, $59 \mathrm{KCl}, 1 \mathrm{CaCl}_{2}, 2 \mathrm{MgCl}_{2}, 11$ EGTA or BAPTA, and $10 \mathrm{HEPES}, \mathrm{pH}$ 7.3. External solutions contained tetrodotoxin $(1 \mu \mathrm{M})$ to block voltagegated sodium conductances. Reagents for physiological solutions were purchased from Sigma (St. Louis, MO).

The bath chamber (volume $0.4 \mathrm{ml}$ ) was continuously perfused at a rate of $0.4 \mathrm{ml} / \mathrm{min}$ using a peristaltic pump. Channel blockers and other reagents were applied using a slightly pressurized large bore (tip diameter $\sim 400 \mu \mathrm{m})$ puffer pipette. The exchange time of the solution surrounding the target cell was estimated to be $250-500 \mathrm{msec}$ based on the change in tip potential of a patch pipette in the normal bath solution to a puff of $100 \mathrm{~mm} \mathrm{KCl}$.

Immunocytochemistry. At the appropriate growth stage, neurons were fixed by immersing coverslips in $4 \%$ paraformaldehyde in PBS (in mM: $137 \mathrm{NaCl}, 2.7 \mathrm{KCl}$, and $10 \mathrm{Sigma}$ catalog \#410-3S phosphate buffer solution, $\mathrm{pH} 7.4$ ) at $37^{\circ} \mathrm{C}$ for $1 \mathrm{hr}$, rinsed in PBS, and stored in $0.1 \%$ paraformaldehyde in PBS at $4^{\circ} \mathrm{C}$ until use. After rinsing stored coverslips in buffer, they were permeabilized in PBS containing 0.3\% Triton X-100 for $15 \mathrm{~min}$ at $37^{\circ} \mathrm{C}$, then rinsed again and blocked for $1 \mathrm{hr}$ at room temperature with $4 \%$ blocking reagent (Boehringer Mannheim, Indianapolis, IN) plus $0.1 \%$ Triton X-100 in PBS. All remaining steps were performed at room temperature. Coverslips were incubated in primary antibody for $2 \mathrm{hr}$ and washed three times for $10 \mathrm{~min}$ each in PBS containing $0.3 \%$ Triton X-100, and then were washed one time for $30 \mathrm{~min}$ in PBS. Coverslips were then incubated in biotinylated goat anti-rabbit antibody (1:1000; Vector Laboratories, Burlingame, CA) for $1 \mathrm{hr}$, washed as above, and amplified using biotin (Berghorn et al., 1994). Coverslips were first incubated in streptavidin-horseradish peroxidase (1:5000; TSA Indirect kit, Dupont NEN, Boston, MA), then in biotinyl tyramide (5 $\mu \mathrm{l} / \mathrm{ml}$, prepared as directed), and then in streptavidin-Cy3 (1:2500; Jackson ImmunoResearch, West Grove, PA), each for $30 \mathrm{~min}$, followed by three washes for 10 min each in PBS plus $0.3 \%$ Triton X-100. They were then mounted in Vectashield (Vector Laboratories) and viewed.

Images were collected with a Zeiss 310 laser-scanning confocal microscope using $543 \mathrm{~nm}$ excitation and a long-pass barrier filter (Chroma, Brattleboro, VT). The fluorescence images presented here were acquired at $512 \times 512$ or $1024 \times 1024$ pixels using a $20 \mu \mathrm{m}$-diameter pin hole (depth of field $\sim 1 \mu \mathrm{m}$ ), and were taken from the lower (nearer the coverslip) portions of each neuron.

Use of the Boehringer blocking reagent in conjunction with the biotin amplification procedure aided in obtaining high resolution images with low background fluorescence.

Morphometrics. After $4 \mathrm{~d}$ in culture, neurons were fixed at room temperature in $4 \%$ paraformaldehyde, and a small drop of the fluorescent lipophilic dye DiI (dissolved in cod liver oil) was placed on a soma. Cells were held at $4^{\circ} \mathrm{C}$ overnight to allow the dye to diffuse through the membrane and then imaged on the confocal microscope (at maximum pin hole diameter). Images were exported in TIFF format to the Optimas image analysis package (Optimas Corporation, Bothell, WA). Measurements were made manually from these images by drawing a cursor across the soma or along a neurite, and length values were exported into a spreadsheet for further analysis.

Materials. Tetrodotoxin, LY294002, wortmannin, ML-9, KN-62, staurosporine, and K252a were all purchased from Calbiochem (San Diego, CA).

The polyclonal antiserum against Kv4.2/3 (Barry et al., 1995) was a gift from Drs. D. M. Barry and J. M. Nerbonne (Department of Pharmacology, Washington University School of Medicine, St. Louis, MO).

Data presentation. All data are presented as mean \pm SD. Statistical comparisons were made using either Student's $t$ test or Dunnett multiple comparisons test as appropriate (Instat; Graph Pad, San Diego, CA). Significance was assessed as $p<0.05$.

\section{RESULTS}

\section{Technical considerations}

All of the data presented here were taken from morphologically identified mouse hippocampal pyramidal neurons (Banker and Cowan, 1977, 1979; Kriegstein and Dichter, 1983) in cultures of cells dissociated from hippocampi isolated from mouse fetuses at embryonic days 15 or 16 and grown in culture for 4-7 d. Kinase inhibitors were added $2 \mathrm{hr}$ after cells were plated and were present continuously until cell-bearing coverslips were rinsed for electrophysiological recording or for immunochemistry.

Separation of three distinct voltage-gated potassium currents, $I_{\mathrm{A}}, I_{\mathrm{D}}$, and $I_{\mathrm{K}}$ (Storm, 1990) followed procedures described in publications from this laboratory and others (Ficker and Heinemann, 1992; Wu and Barish, 1992). Briefly, sodium currents were blocked by adding TTX $(1 \mu \mathrm{M})$ to all external solutions; calcium currents and calcium-dependent potassium currents were minimized by using physiological $\left[\mathrm{Ca}^{2+}\right]$ in external solutions $(1.8$ $\mathrm{mm}$ ), by incorporating potassium fluoride in internal solutions, 
and by intracellular dialysis with EGTA- or BAPTA-containing solutions. Under these conditions we have not observed any effect on potassium currents of adding $\mathrm{Ni}^{2+}$ or $\mathrm{Cd}^{2+}$ to external solutions at blocking concentrations. Neurons were held under voltage clamp at $-80 \mathrm{mV}$, and maximal availability of all voltagegated currents was achieved by imposing a 1000-msec-long conditioning hyperpolarization to $-120 \mathrm{mV}$. Potassium currents were measured at a test voltage of $+40 \mathrm{mV}$, at which $I_{\mathrm{A}}$ is maximally activated. $I_{\mathrm{A}}$ was defined as the current sensitive to a conditioning 50-80-msec-long prepulse to $-40 \mathrm{mV}, I_{\mathrm{D}}$ as the current sensitive to $100-200 \mu \mathrm{M} 4-\mathrm{AP}$, and $I_{\mathrm{K}}$ as the TEAsensitive current remaining after block of $I_{\mathrm{A}}$ by the prepulse and block of $I_{\mathrm{D}}$ by exposure to 4-AP. An example of this separation is shown in Figure 3.

Cell capacitance was also measured as described in previous publications (Wu and Barish, 1992). After establishing the initial high resistance seal and in-amplifier compensation for pipette and patch membrane capacitance, the patch was ruptured and the whole-cell condition was established. Before imposing any additional capacitance compensation, a series of 10 short (20-mseclong) depolarizations from -70 to $-60 \mathrm{mV}$ were delivered, and the currents were averaged. Whole-cell capacitance was evaluated by integrating the area under the capacity transient to measure $Q$ (total charge transferred) and computed from the relation $C=$ $Q / \Delta V$, where $C$ is cell capacitance and $\Delta V$ is the magnitude of the voltage step.

We believe that measurements of whole-cell capacitance and voltage-gated potassium currents and analyses of membrane insertion were all made from a somatodendritic compartment subject to reasonable voltage control and also susceptible to inhibition of membrane insertion. In cultured neurons A-type potassium channels are found on somata and apical dendrites (as assessed during single channel recording; R.-L. Wu and M. E. Barish, unpublished observations), and the cross-sectional area of this compartment, as described below, was reduced by kinase inhibitors. Cable analysis of hippocampal pyramidal neurons in situ (Johnston and Brown, 1984) indicates that even rapid synaptic events located on the apical dendrite can be well clamped. Thus, the A-type potassium channel-bearing region of cell membrane could be subjected to electrophysiological analysis, and it was also actively inserting membrane during this developmental period.

\section{Overview}

The data that follows are grouped into three sections: first, the effects of manipulating neurite outgrowth by varying the composition of the culture medium; second, the effects of inhibiting kinases implicated in receptor signaling and/or in control of exocytosis; and third, the effects of two broad spectrum kinase inhibitors.

\section{Culture medium and neurite outgrowth}

Because we had previously observed that pyramidal neurons growing in contact with astroglial cells had enhanced membrane area, we wished to separate effects of astroglial contact from those related to membrane insertion and neurite outgrowth. To do this we compared neurons grown in serum-containing and serum-free media. Neurons grown in serum-free medium are commonly observed to have greater neurite outgrowth than neurons grown in serum-containing medium (Brewer et al., 1993; Brewer, 1995), and serum-free medium also discourages proliferation of astroglial cells and their precursors (Brewer et al., 1993). For these particular experiments we used a serum-containing medium consisting of MEM supplemented only with $10 \%$ fetal calf serum (MEM-FCS) and a serum-free medium consisting of Neurobasal supplemented only with B-27 additive (Neurobasal-B-27; Brewer et al., 1993).

Images of representative pyramidal neurons grown in these two media are shown in Figure $1 A$. Increased neurite outgrowth in the absence of astroglial cells is evident for the NeurobasalB-27 cultures. Neurons in the MEM-FCS cultures grew in contact with a sparse astroglial monolayer and showed fewer neurite branches.

Comparison of the electrophysiological properties of these neurons (Fig. $1 B$ ) suggests that neurite outgrowth (membrane expansion) may regulate $I_{\mathrm{A}}$ development, and this process may be downstream of contact with astroglial cells. Although membrane area (determined as whole-cell capacitance) was comparable in the two neuronal populations, $I_{\mathrm{A}}$ amplitude (top row) and $I_{\mathrm{A}}$ density (current amplitude normalized to cell capacitance and expressed as picoamperes per picofarad; bottom row) was increased significantly in neurons grown under serum-free conditions. This result is contrary to what would be expected if astroglial contact alone was regulating appearance of $I_{\mathrm{A}}$ and instead suggests that, in these cultures, greater neurite outgrowth was responsible for enhanced $I_{\mathrm{A}}$ development.

Interestingly, $I_{\mathrm{D}}$ amplitude and density showed some reci procity with $I_{\mathrm{A}}$; this reached statistical significance for $I_{\mathrm{D}}$ density. A similar relationship between $I_{\mathrm{A}}$ and $I_{\mathrm{D}}$ was seen in our previous investigation of the effects of astroglial contact ( $\mathrm{Wu}$ and Barish, 1994).

Because the growth-promoting effects of glial cells on neurons are well known (Noble et al., 1984; Fallon, 1985; Pixley et al., 1987), the results of this experiment further suggested that astroglial cells might exert their influence on $I_{\mathrm{A}}$ development ( $\mathrm{Wu}$ and Barish, 1994) through programs of membrane expansion and neurite outgrowth and parallel insertion of A-type potassium channels. We therefore examined intracellular signaling pathways that may be involved in these processes.

\section{Kinases implicated in control of membrane trafficking and exocytosis}

The experiments presented in this section were all performed using neurons growing on a cocultured astroglial monolayer and were designed to perturb the potassium current development promoted by astrocyte contact. The kinases targeted by the inhibitors used were as follows: PI 3-kinases by LY294002 or wortmannin; myosin light chain kinase by ML-9; CaMKII by KN-62; PKC by bisindolymaleimide, calphostin C, or K-252b; and multiple serine-threonine and tyrosine kinases by staurosporine or K-252a.

Inhibition of phosphatidylinositol 3-kinase by LY294002 and wortmannin. PI 3-kinases are a family of lipid kinases (Zvelebil et al., 1996) that catalyze phosphorylation of inositol at the D-3 position. PI 3-kinases are elements in the signaling pathways initiated by receptor tyrosine kinases (Kapeller and Cantley, 1994), and regulate, among other activities, membrane trafficking (De Camilli et al., 1996; Shepherd et al., 1996). Wortmannin and LY294002 (Vlahos et al., 1994) are structurally unrelated membrane-permeant inhibitors of PI 3-kinases.

Exposure of developing neurons to micromolar concentrations of LY294002 or wortmannin reduced both membrane area and neurite outgrowth. Shown in Figure 2, $A 1$ and $A 2$, are fluorescence images of individual neurons labeled with the membrane 
A

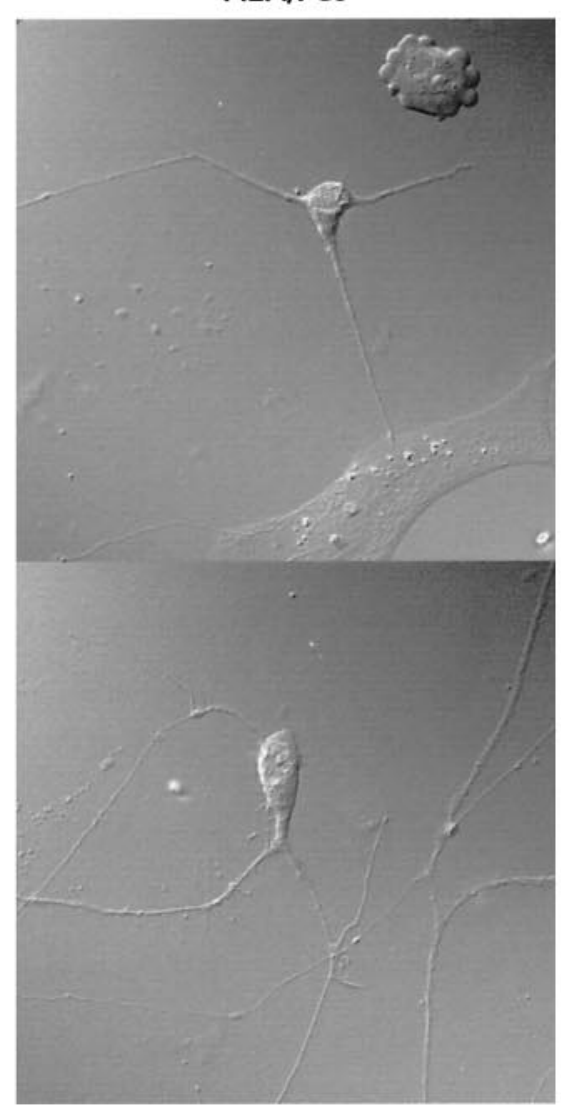

Neurobasal/B-27

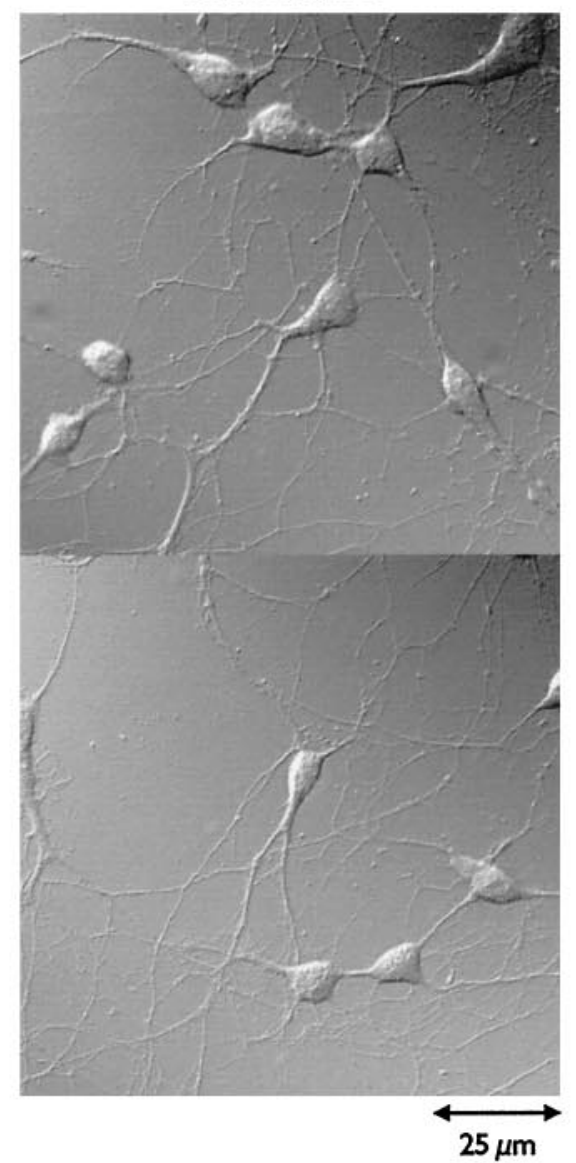

B
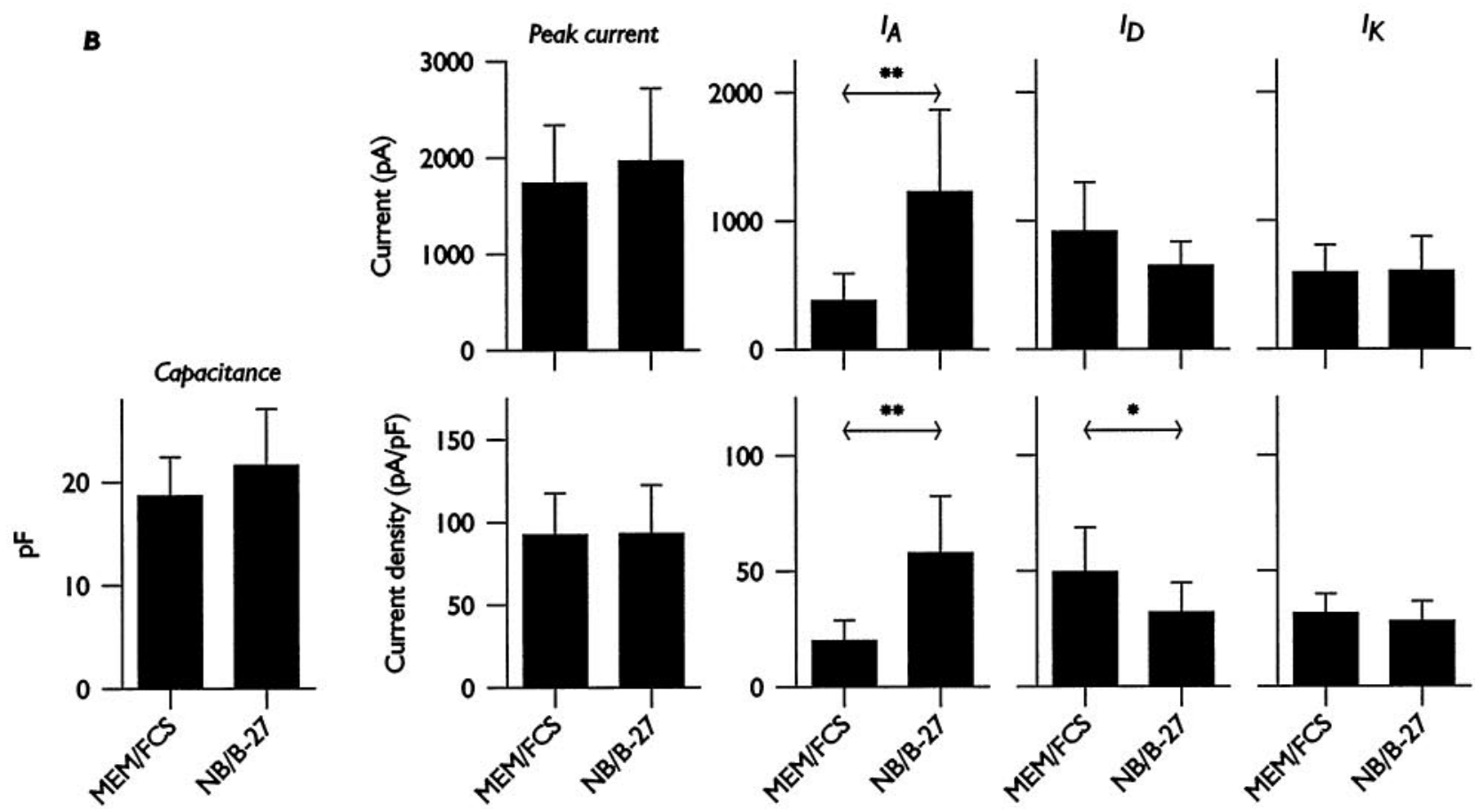

Figure 1. A, Comparison of neuronal morphology after culture in serum-containing (MEM-FCS) and serum-free (Neurobasal-B-27) media. The images illustrate enhanced neurite outgrowth by neurons cultured in Neurobasal-B-27 medium. Neurons had been in culture for 5 d. $B$, Effects of the culture medium on potassium current development. $I_{\mathrm{A}}$ was enhanced in neurons grown in Neurobasal-B-27 medium despite their lack of astroglial contact. Numbers of cells: 10 NB-B-27 and 8 MEM-FCS. In this and subsequent figures, ${ }^{*}$ denotes $p<0.05 ; * *$ denotes $p<0.01$; and $* * *$ denotes $p<0.001$. 

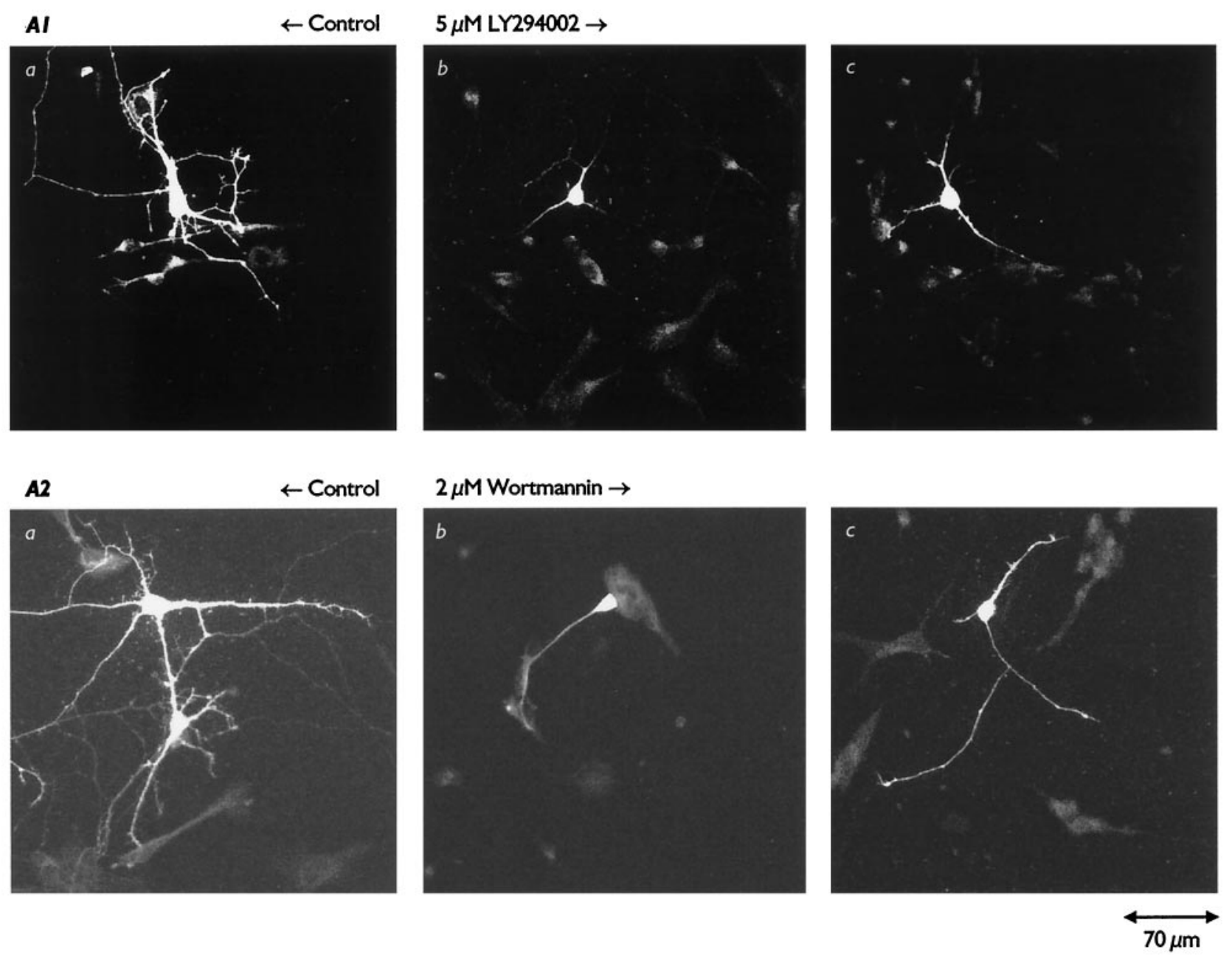

BI

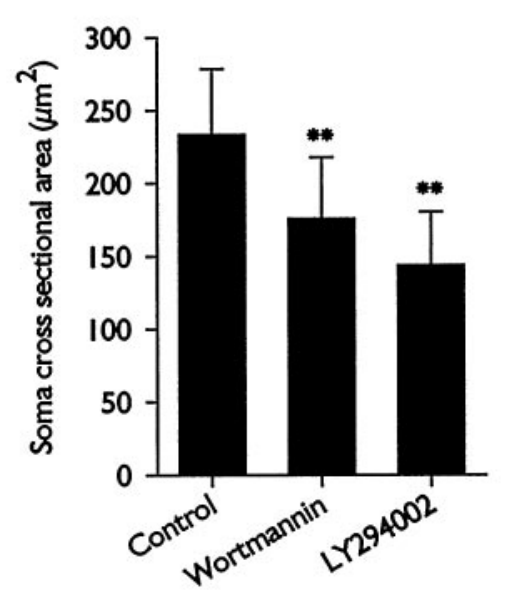

B2

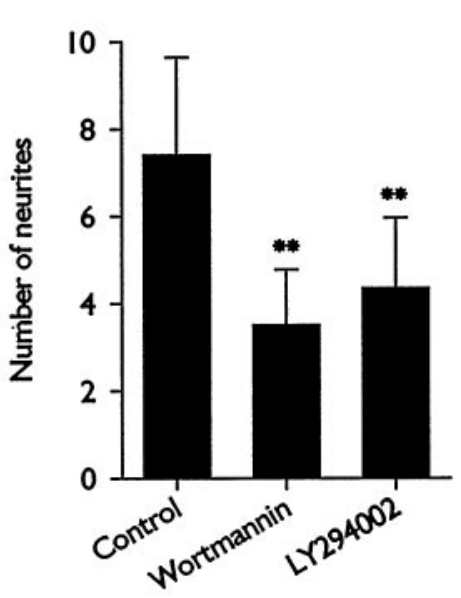

B3

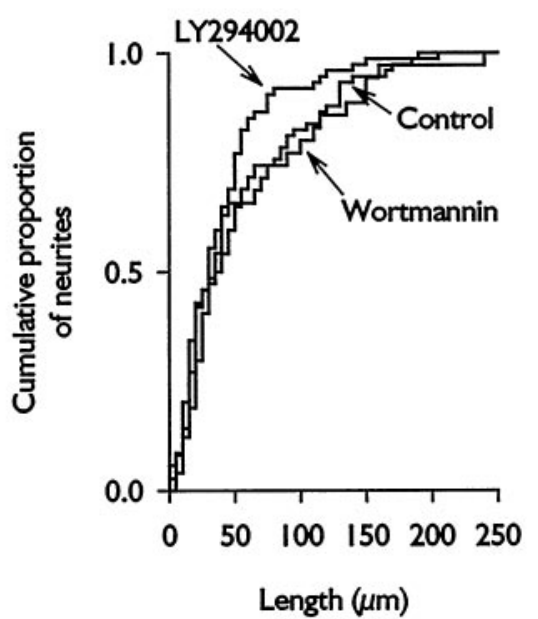

Figure 2. A, Morphology of neurons grown in the presence of PI 3-kinase inhibitors; exposure to LY294002 (A1) or wortmannin (A2) reduced soma size and neurite outgrowth. Neurons were labeled by placing a small drop of DiI dissolved in oil on a neuron soma, as described in Materials and Methods. Shown for each inhibitor are representative examples of a control image (note that two neurons are labeled in the wortmannin control) and two experimental images. $B$, Measurements of neurons imaged as above. Inhibition of PI 3-kinase reduced somatic cross-sectional area $(B 1)$ and numbers of neurites (B2). The lengths of shorter neurites (i.e., lengths $<30-40 \mu \mathrm{m}$ ) were minimally effected, but exposure to LY294002 affected growth of longer neurites (B3, cumulative analysis). Numbers of cells analyzed: 10 control, 17 LY294002, and 10 wortmannin. 
Control

\section{Total voltage- gated potassium current}
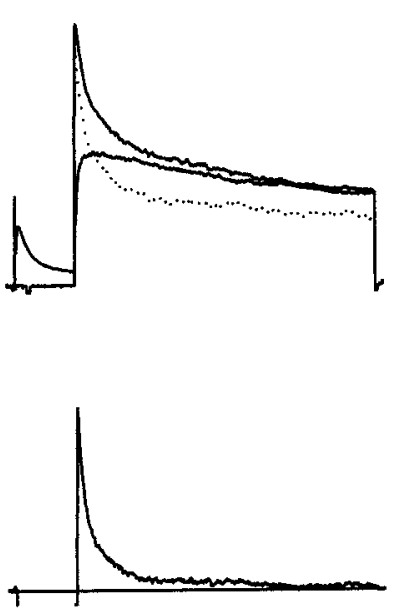

LY294002
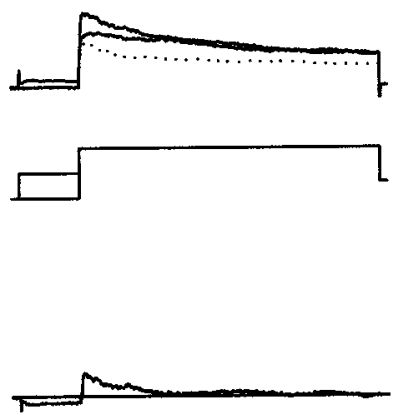

Figure 3. Whole-cell potassium currents recorded at $+40 \mathrm{mV}$ from control and LY294002treated neurons. The traces in the top row are currents recorded after conditioning prepulses to -120 and $-40 \mathrm{mV}$ (solid traces). Addition of $100 \mu \mathrm{M} 4$-AP to the bath reduced the current evoked after the prepulse to $-120 \mathrm{mV}$ (dotted trace). The traces in the bottom rows illustrate isolation of the individual currents, as described in Results. In this example, $I_{\mathrm{A}}$ was almost completely eliminated in the cell grown for $4 \mathrm{~d}$ in the presence of LY294002 $(5 \mu \mathrm{M}) . I_{\mathrm{D}}$ and $I_{\mathrm{K}}$ were smaller in the LY294002-exposed neuron, as expected from the reduced membrane area of these cells.

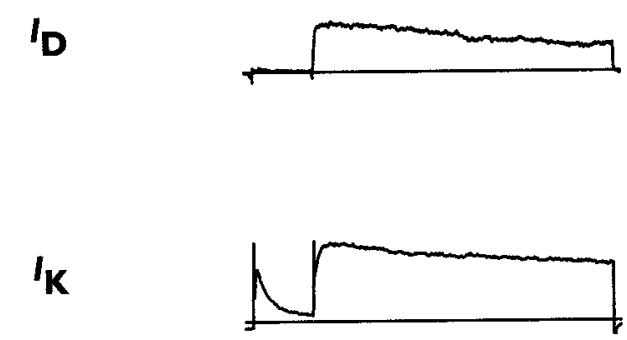

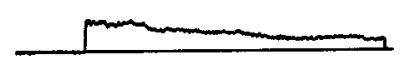

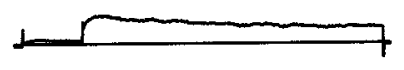

probe DiI. The control (Fig. 2A1a, A2a) and experimental (Fig. $2 A 1 b, c, A 2 b, c)$ fields presented illustrate the reduced somatic diameters and neurite numbers of neurons grown in the presence of LY294002 (5 $\mu \mathrm{M})$ or wortmannin $(2 \mu \mathrm{M})$.

We quantified membrane area and neuronal morphology in terms of (1) somatic cross-sectional area, approximated as an ellipse and determined from measurements of major and minor axes, (2) numbers of first order $\left(1^{\circ}\right)$ neurites emerging from the soma or apical dendrite, and (3) the lengths of these neurites. The major effects of PI 3-kinase inhibitors were to reduce somatic size and numbers of $1^{\circ}$ neurites, with smaller effects on the lengths of individual neurites. Somatic cross-sectional area (Fig. 2B1) was reduced to $\sim 62 \%$ of control by LY294002 and to $\sim 75 \%$ of control by wortmannin. Numbers of $1^{\circ}$ neurites per cell (Fig. 2B2) were reduced to $\sim 60 \%$ of control by LY294002 and to $\sim 47 \%$ of control by wortmannin. Surprisingly, exposure to LY294002 or wortmannin did not noticeably affect the growth of those shorter neurites that did emerge (i.e., neurites with lengths $<30-40 \mu \mathrm{m}$ ), but growth of longer neurites (i.e., with lengths more than $\sim 50 \mu \mathrm{m}$ ) was selectively disturbed by LY294002 (Fig. 2B3).
Growth in the presence of PI 3-kinase inhibitors also affected development of voltage-gated potassium currents. Recordings shown in Figure 3, made from a control neuron and a neuron exposed to LY294002, illustrate the selective deficit in $I_{\mathrm{A}}$ induced by the inhibitor. Shown in the top row are the total potassium currents recorded during test depolarizations to $+40 \mathrm{mV}$ after conditioning prepulses to -120 or $-40 \mathrm{mV}$ (solid lines). An additional trace (dotted line) shows total current recorded after a prepulse to $-120 \mathrm{mV}$ in the presence of $100 \mu \mathrm{M} 4$-AP. The traces below show $I_{\mathrm{A}}, I_{\mathrm{D}}$, and $I_{\mathrm{K}}$ isolated as described above and illustrate the almost total loss of $I_{\mathrm{A}}$ in the neuron exposed to LY294002. $I_{\mathrm{D}}$ and $I_{\mathrm{K}}$ are also reduced in amplitude but not eliminated, as expected given the reduced size of neurons grown in the presence of LY294002.

Comparison of electrophysiological measurements made from populations of pyramidal neurons exposed to either LY294002 or wortmannin with control neurons showed reduced total cell capacitance (an index of membrane area; Fig. 4A1,2), and reduced amplitudes of $I_{\mathrm{A}}, I_{\mathrm{D}}$, and $I_{\mathrm{K}}$ (Fig. 5A1,2). For example, exposure to LY294002 reduced total cell capacitance to $47 \%$ of control, $I_{\mathrm{A}}$ amplitude to $18 \%$ of control, $I_{\mathrm{D}}$ amplitude to $51 \%$ of control, and 
Capacitance

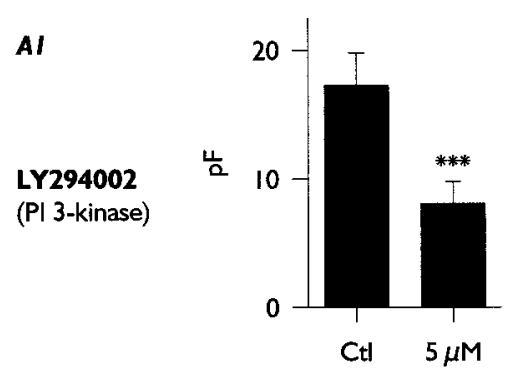

A2

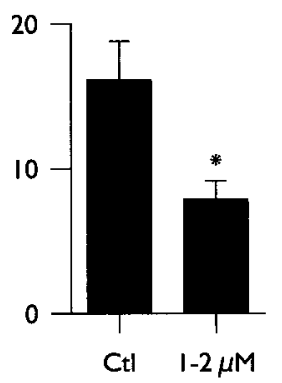

B
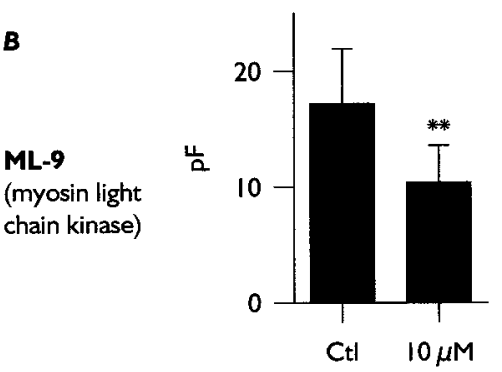

c
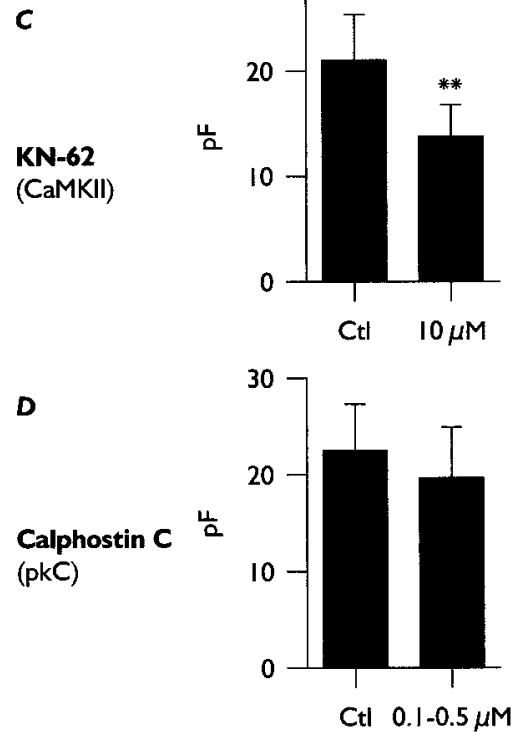

Figure 4. Effects of growth in the presence of kinase inhibitors on wholecell capacitance, determined as described in the Results. Shown are data for LY294002 (A1), wortmannin (A2), ML-9 (B), KN-62 (C), and calphostin C $(D)$; putative targets of these inhibitors are indicated in parentheses. Membrane area was reduced by all inhibitors except calphostin C. Data presented in Figures 4-6 are drawn from the same population of neurons, and for all three figures numbers of cells are: wortmannin, 10 control, 11 experimental; LY294002, 3 control, 5 experimental; $M L-9$, 13 control, 10 experimental; $K N-62,8$ control, 8 experimental; and calphostin $C, 14$ control, 17 experimental.
$I_{\mathrm{K}}$ amplitude to $37 \%$ of control. When expressed as current density (Fig. 6A1,2), LY294002 reduced $I_{\mathrm{A}}$ density to $40 \%$ of control without significantly affecting densities of $I_{\mathrm{D}}$ or $I_{\mathrm{K}}$, and the same pattern was seen with wortmannin. Thus, LY294002 and wortmannin reduced $I_{\mathrm{D}}$ and $I_{\mathrm{K}}$ in proportion to their effects on membrane area, whereas the reduction in $I_{\mathrm{A}}$ was greater than expected based on cell size.

The multimeric ion channels mediating $I_{\mathrm{A}}$ (referred to here as A-type potassium channels) are likely to incorporate Kv4.2 and/or Kv4.3 protein in their pore-forming subunits (Serôdio et al., 1994; Keros and McBain, 1997; Johns et al., 1997), although they may well not be composed exclusively of Kv4.2 and/or Kv4.3 subunits. We examined the subcellular localization of A-type potassium channels under control conditions and after exposure to kinase inhibitors using an antiserum raised against a C-terminal sequence found in both Kv4.2 and Kv4.3 subunits (Barry et al., 1995). The staining pattern observed by immunofluorescence using this antiserum is referred to here as Kv4.2/3 immunoreactivity. Note that this antiserum was raised against an intracellular epitope and, therefore, that all images were acquired from permeabilized cells and, therefore, portray both internal and plasmalemmal distributions of immunoreactivity.

The images presented in Figures 7 and 8 indicate that Kv4.2/3 immunoreactivity was profoundly altered by exposure to LY294002. In control neurons illustrated in Figure $7 A 1-A 4$ (shown are pairs of Nomarski DIC and confocal immunofluorescence images for two representative neurons), Kv4.2/3 immunoreactivity was dense, granular, and distributed throughout somata and dendritic processes. A void area created by the nucleus was faintly seen in these neurons. In neurons examined in other experiments this void area was often less apparent. Immunoreactivity was not evident in longer, more tubular axonal processes (Fig. 7A2, A4, arrowheads).

Processes displaying Kv4.2/3 immunoreactivity were identified as dendritic because of their tapering morphology and relatively short length (Bartlett and Banker, 1984a,b; Dotti et al., 1988) and because they express the dendritic marker MAP2 (Caceres et al., 1984; data not shown). These observations are consistent with other reports of Kv4.2/3 immunoreactivity localization to somata and dendrites of hippocampal pyramidal neurons in situ and in culture (Sheng et al., 1992; Maletic-Savatic et al., 1995b; Tsaur et al., 1997).

The size and distribution of the granular Kv4.2/3immunoreactive punctata are shown in more detail in Figure $8 A$, which is taken from the region of the soma of the neuron in Figure $7 A 3$ indicated by the arrow. In this enlargement each pixel represents a square $\sim 0.2 \times 0.2 \mu \mathrm{m}$; individual punctata had diameters of $0.5-0.75 \mu \mathrm{m}$. We assume that these punctata represent aggregates of membranous structures bearing Kv4.2/3 subunits, perhaps the tubulovesicular transport vesicles described by Nakata et al. (1998).

For neurons grown in the presence of LY294002, Kv4.2/3 immunoreactivity was dramatically reduced, as judged by the much lower density of immunoreactive punctata (Fig. 7B3,4). These punctata were distributed as in control neurons; throughout somata and dendrites but not axons and without significant accumulation in any one region. Exposure to LY294002 reduced the density of punctata, but those punctata that were evident had diameters and luminance values similar to those seen in control neurons (Fig. $8 B$ ). 
Peak current

AI

LY294002

(PI 3-kinase)

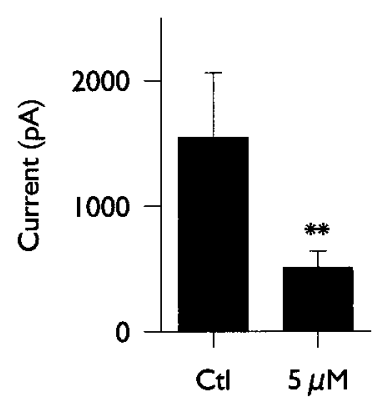

$I_{A}$
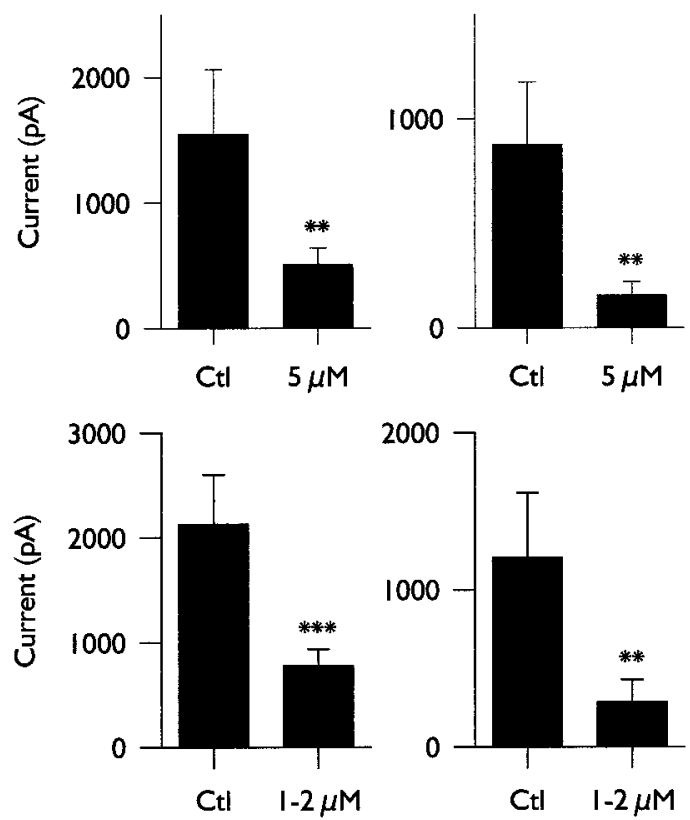

B

ML-9

(myosin light chain kinase)
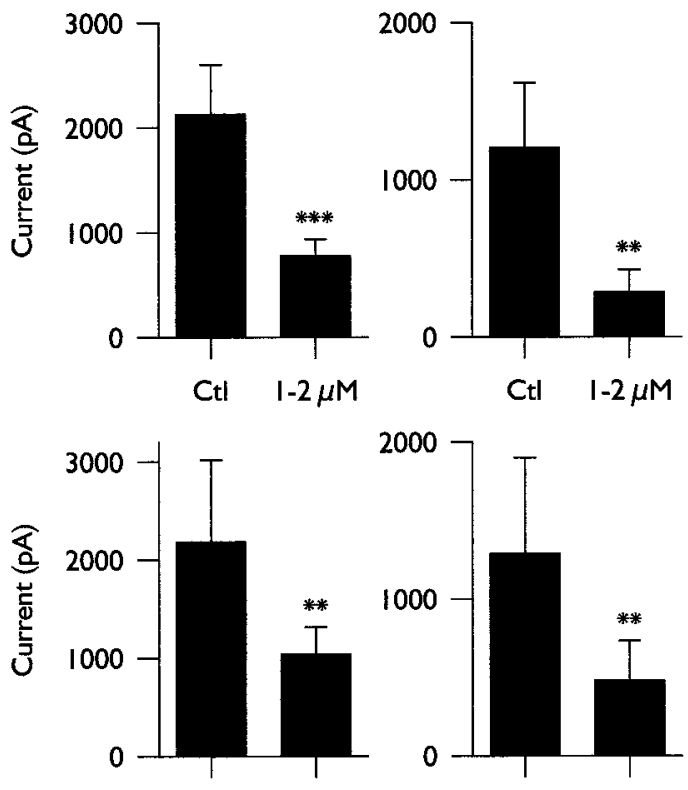

A2

Wortmannin (PI 3-kinase)

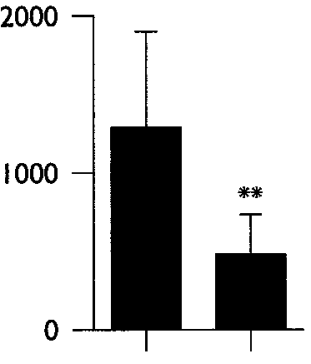

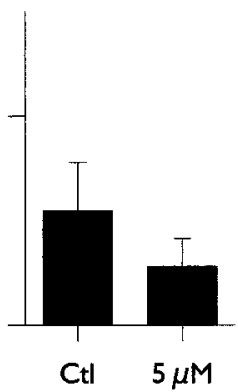

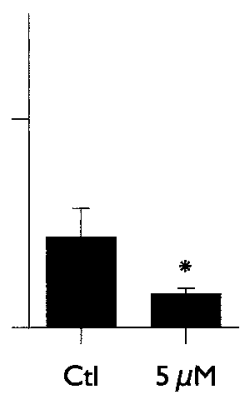

C

KN-62

(CaMKII)
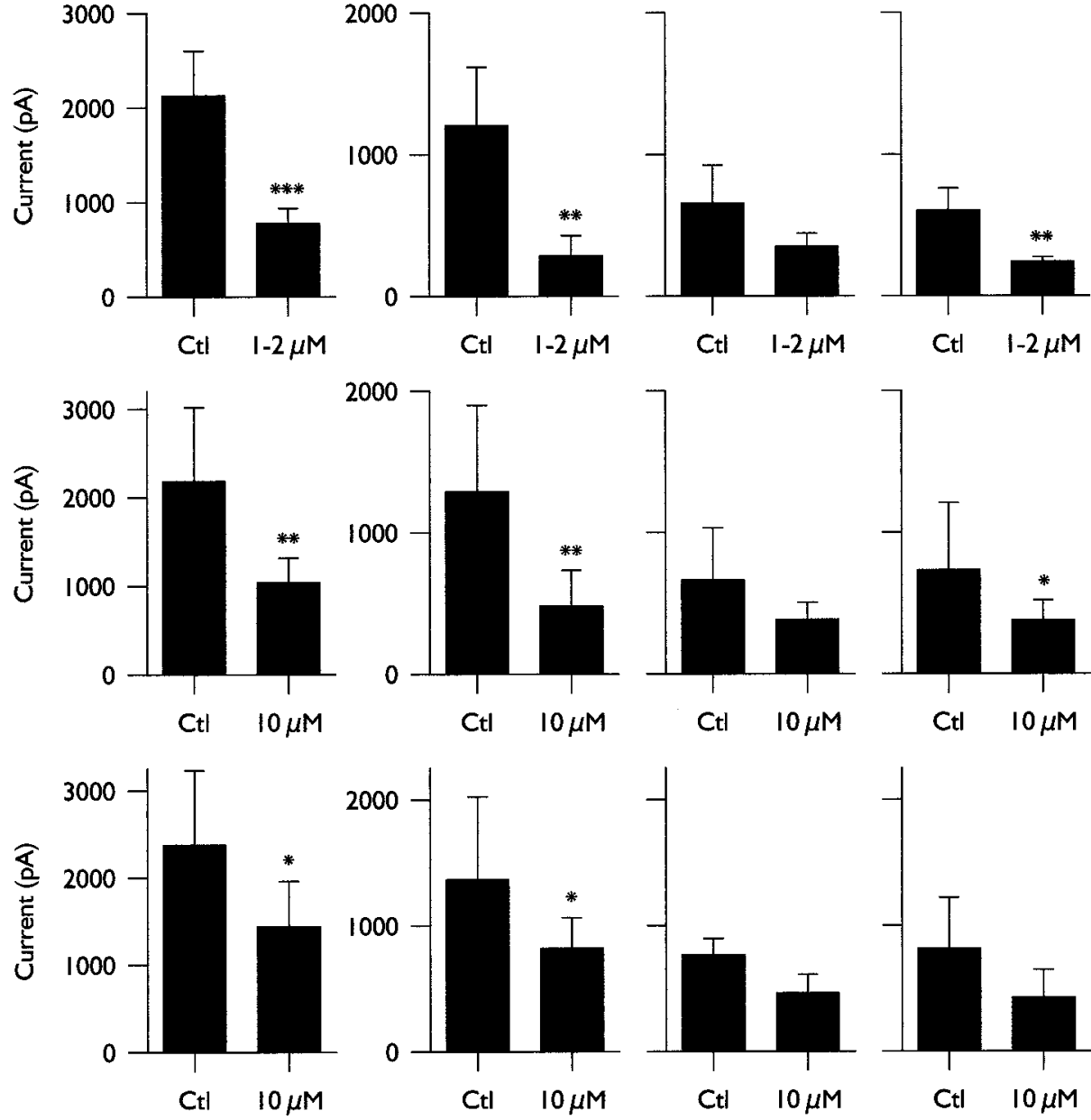

Ctl $\quad 10 \mu \mathrm{M}$

CtI $10 \mu \mathrm{M}$
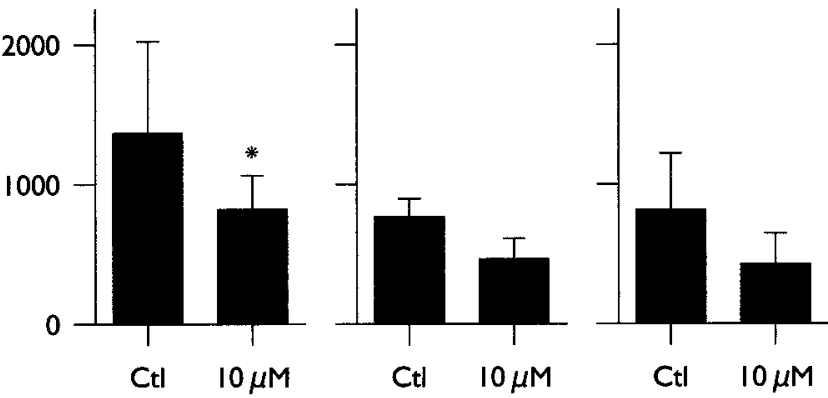

D

Calphostin C (pkC)
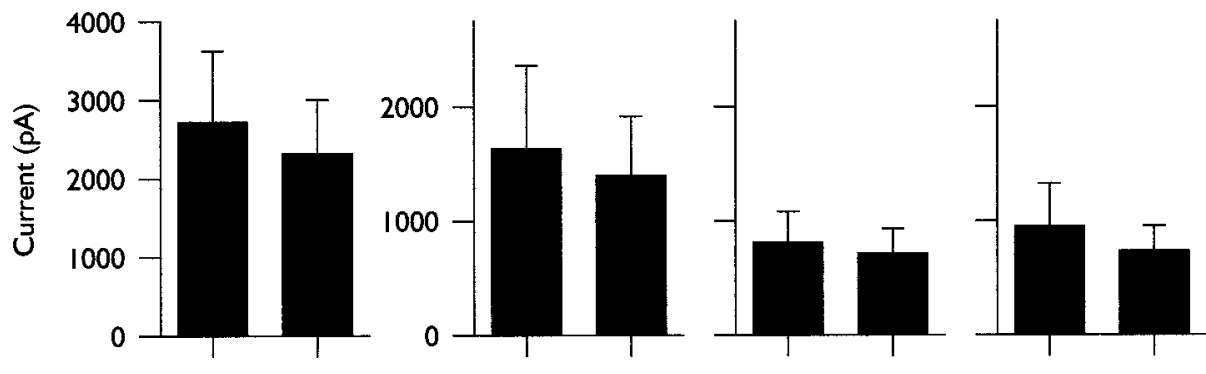

Ctl $\quad 0.1-0.5 \mu \mathrm{M}$

CtI $\quad 0.1-0.5 \mu \mathrm{M}$

Ctl $\quad 0.1-0.5 \mu \mathrm{M}$

Ctl $\quad 0.1-0.5 \mu \mathrm{M}$

Figure 5. Effects of growth in the presence of kinase inhibitors on amplitudes (as picoamperes measured at $+40 \mathrm{mV}$ ) of voltage-gated potassium currents, determined as described in Results. Shown are data for $L Y 294002$ (A1), wortmannin (A2), ML-9 (B), KN-62 (C), and calphostin C (D); putative targets of these inhibitors are indicated in parentheses. $I_{\mathrm{A}}, I_{\mathrm{D}}$, and $I_{\mathrm{K}}$ amplitudes were all reduced by all inhibitors except calphostin C; the largest and the most significant effects were seen for inhibitors of PI 3-kinases and for $I_{\mathrm{A}}$ and $I_{\mathrm{K}}$ (a clear trend was seen for $I_{\mathrm{D}}$ ). 
AI

LY294002

(PI 3-kinase)

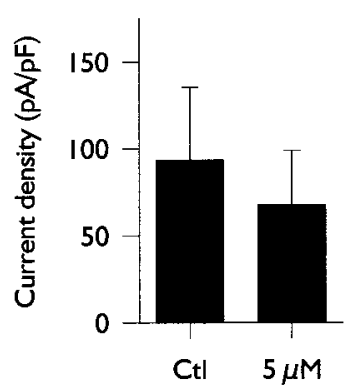

A2

Wortmannin (PI 3-kinase)

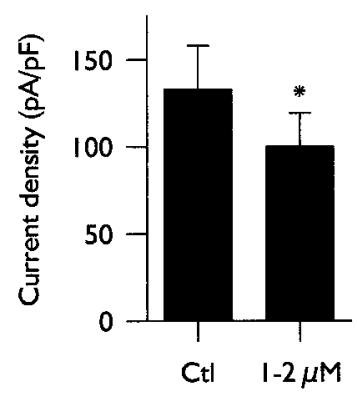

$\boldsymbol{B}$

ML-9

(myosin light chain kinase)

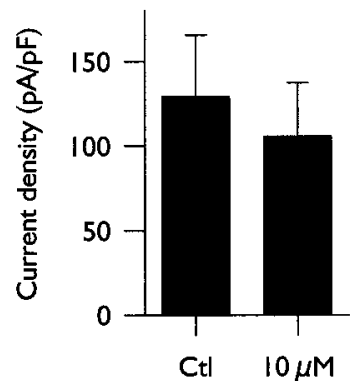

c

KN-62

(CaMKII)

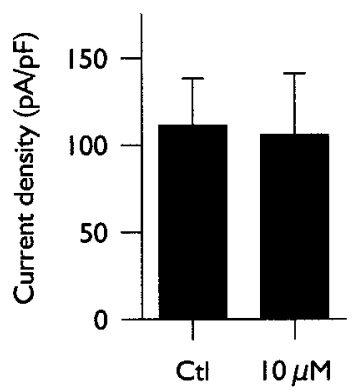

D

Calphostin C (pkC)
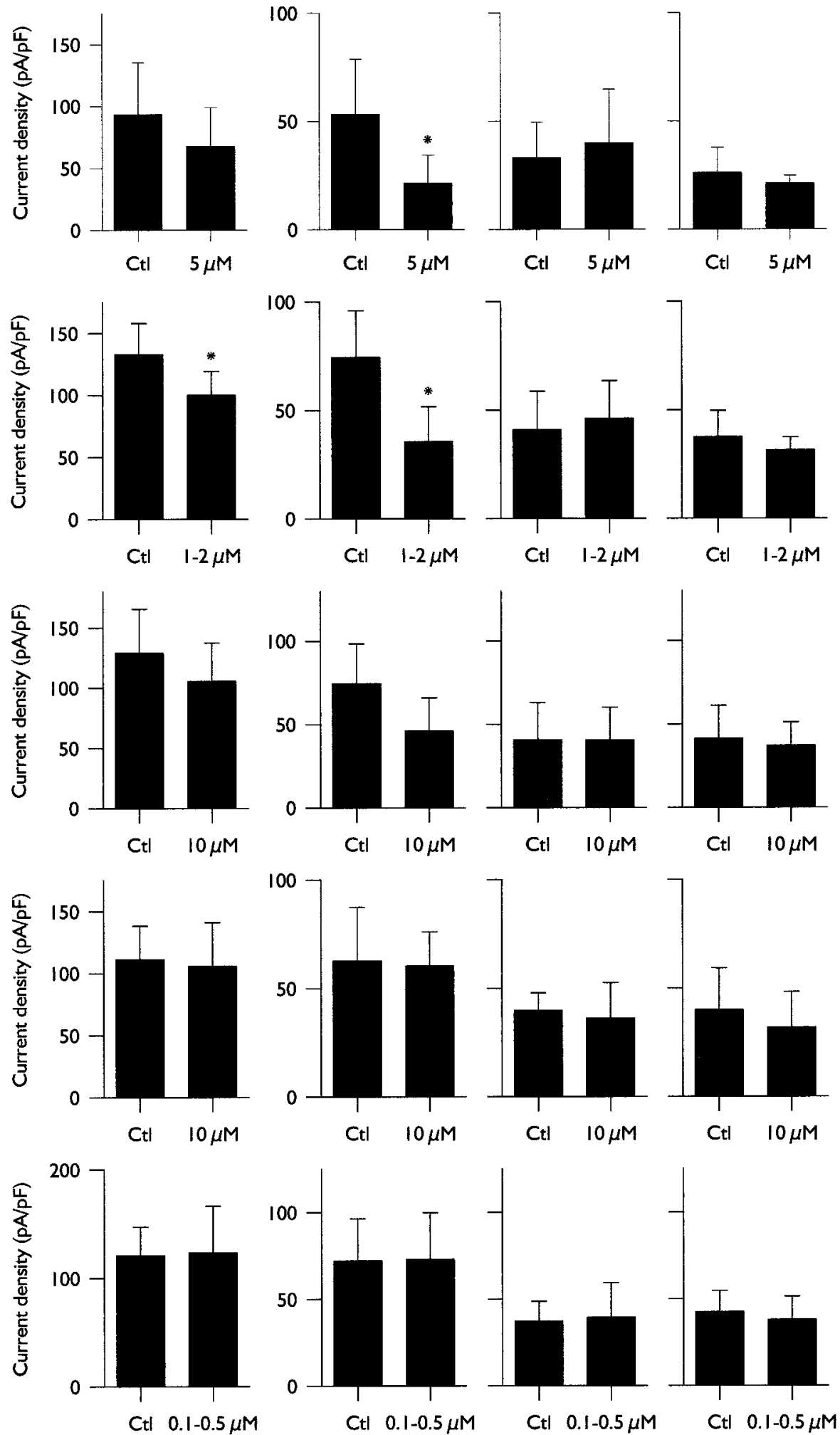

Ct| $\quad 0.1-0.5 \mu \mathrm{M}$

Figure 6. Effects of growth in the presence of kinase inhibitors on densities (as picoamperes per picofarad measured at $+40 \mathrm{mV}$ ) of voltage-gated potassium currents, determined as described in Results. Shown are data for LY294002 (A1), wortmannin (A2), ML-9 (B), KN-62 (C), and calphostin C $(D)$; putative targets of these inhibitors are indicated in parentheses. $I_{\mathrm{A}}$ density was significantly reduced only by LY294002 and wortmannin; a trend that did not reach significance was evident for ML-9. In contrast, $I_{\mathrm{A}}$ density was not altered by exposure to KN-62 or calphostin C, nor were densities of $I_{\mathrm{D}}$ or $I_{\mathrm{K}}$ affected by kinase inhibition. 
Nomarski DIC

\section{Control}

LY294002

(PI 3-kinase)

Figure 7. Distributions of Kv4.2/3 immunoreactivity in control pyramidal neurons $(A)$ and alterations induced by growth in the presence of the kinase inhibitors LY294002 (B), ML-9 $(C)$, and $\mathrm{KN}-62(D)$. In each case, Nomarski DIC and fluorescence images are shown for two representative neurons. The arrows in the fluorescence images indicate areas enlarged in Figure 8. A, Control neurons demonstrating the disperse and granular character of the Kv $4.2 / 3$ immunoreactivity. Strong Kv4.2/3 immunoreactivity is found only in somata and dendrites; tubular axonal structures $(A 2$, $A 4$, arrowheads) are devoid of signal. $B$, In neurons exposed to LY294002, the density of Kv4.2/3-immunoreactive punctata was greatly reduced, but their distribution was not significantly affected. $C$, In neurons exposed to ML-9, the density of Kv4.2/3immunoreactive punctata was reduced but not to the extent seen with LY294002. In somata, punctata were found in a perinuclear array surrounding a void volume occupied by the nucleus; this was much more evident in ML-9-treated neurons than in control neurons or neurons exposed to the other inhibitors. $D$, In neurons exposed to $\mathrm{KN}-62$, the density of $\mathrm{Kv} 4.2$ / 3-immunoreactive punctata was only slightly reduced from the control, and, as in control neurons, punctata were distributed throughout the soma and major dendrites. (Figure and legend continue)

\section{ML-9 \\ (myosin light chain kinase)}

\section{KN-62} (CaMKII)
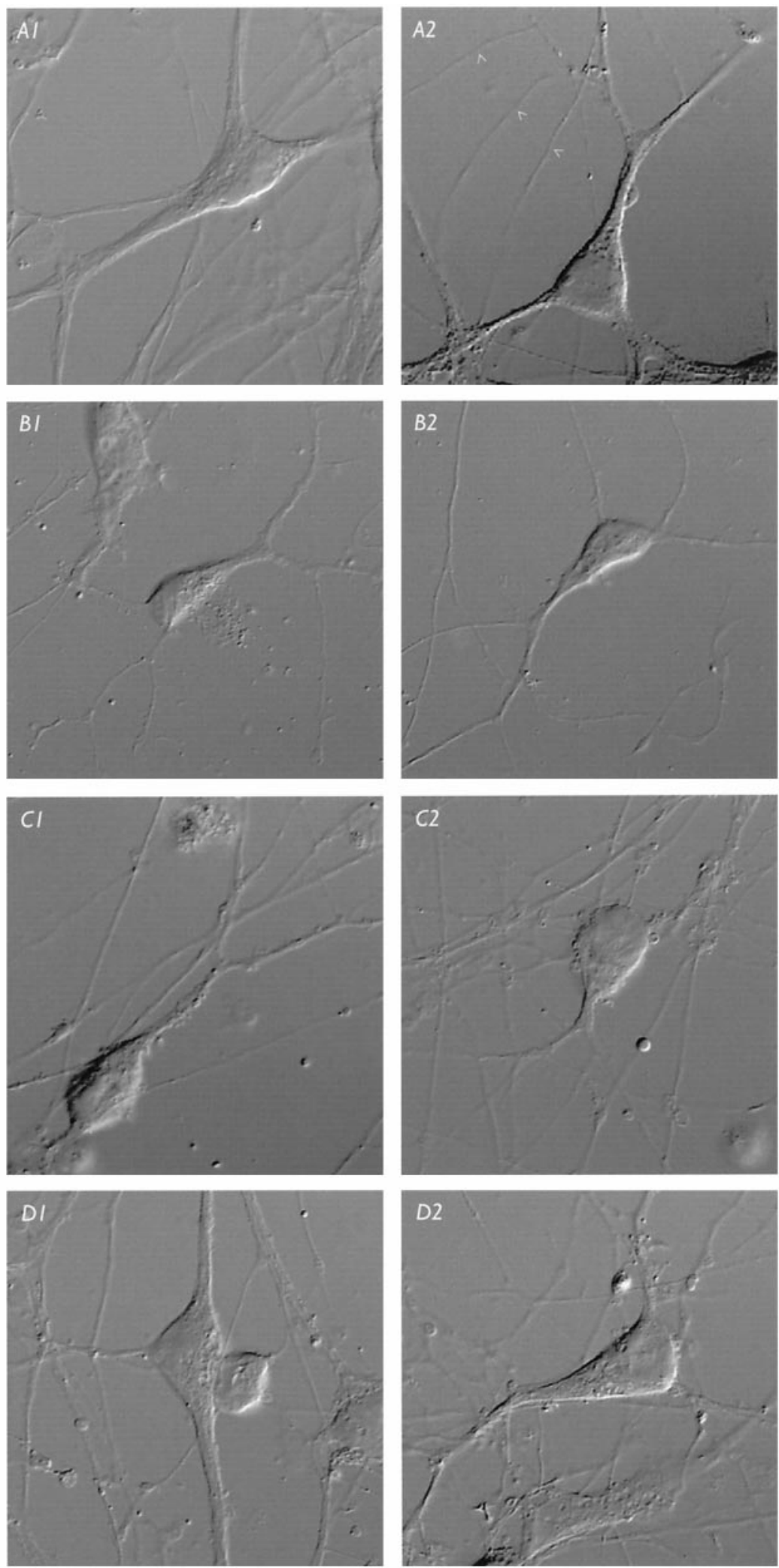

Inhibition of myosin light chain kinase by ML-9. Multiple members of the myosin superfamily are found in brain and may participate in aspects of membrane trafficking, including exocytosis (Mermall et al., 1998). We used the myosin light chain kinase inhibitor ML-9 (Saitoh et al., 1986).
In electrophysiological experiments, ML-9 reduced total cell capacitance in a dose-dependent manner, with reduction to $60 \%$ of control by $10 \mu \mathrm{M}$ ML-9 (Fig. $4 B$ ). At this concentration ML-9 also reduced $I_{\mathrm{A}}$ amplitude to $37 \%$ of control, $I_{\mathrm{D}}$ amplitude to $58 \%$ of control, and $I_{\mathrm{K}}$ amplitude to $51 \%$ of control (Fig. $5 B$ ). ML-9 

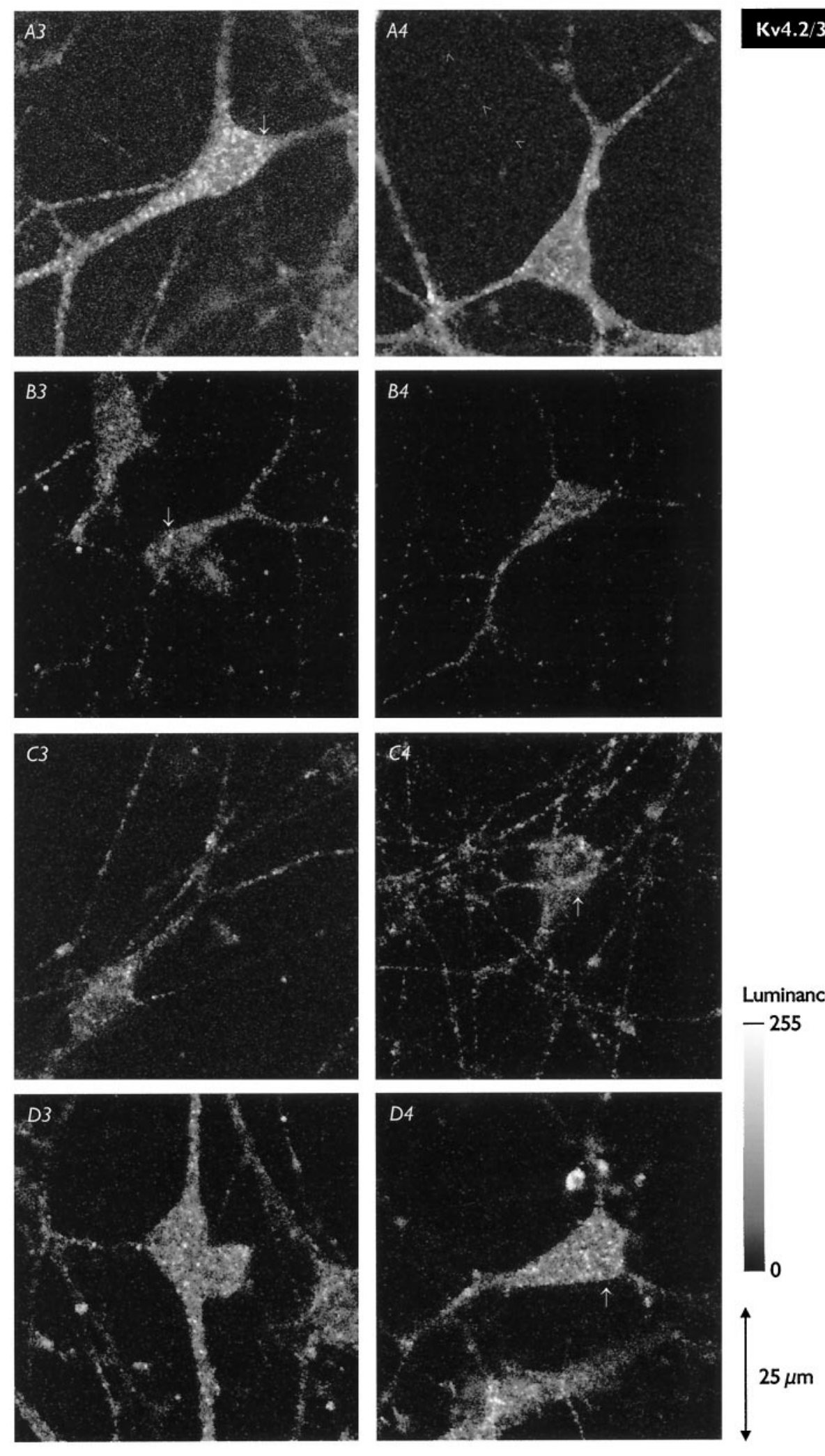

\section{Kv4.2/3 immunoreactivity}

\section{Luminance}

$-255$

$\leftarrow$

The images in Figures 7 and 8 were all acquired from two sets of sister coverslips that were grown, processed for immunochemistry, and imaged in parallel. Numbers of neurons analyzed: 17 control, 10 LY294002, $24 \mathrm{ML}-9$, and $10 \mathrm{KN}-62$. In general, comparisons of Kv4.2/3 immunoreactivity were performed 2-4 times for each kinase inhibitor. The luminance scale applies to all fluorescence images. Control images, in which the primary antibody was omitted, showed only background luminance (as between punctata; images not shown). reduced $I_{\mathrm{A}}$ density (although this did not quite reach statistical significance) without affecting the densities of the other potassium currents (Fig. 6B).

Nomarski DIC images of pyramidal neurons grown in the presence of ML-9 (Fig. 7C1,2) indicated that exposure to ML-9 re- sulted in somata that were less triangular and more rounded than those of control neurons (Fig. 7A1,2). ML-9-treated neurons showed reduced density of Kv4.2/3-immunoreactive punctata (Fig. $7 C 3,4)$, and these punctata showed greater accumulation in a perinuclear rind than was evident in control neurons or neurons 

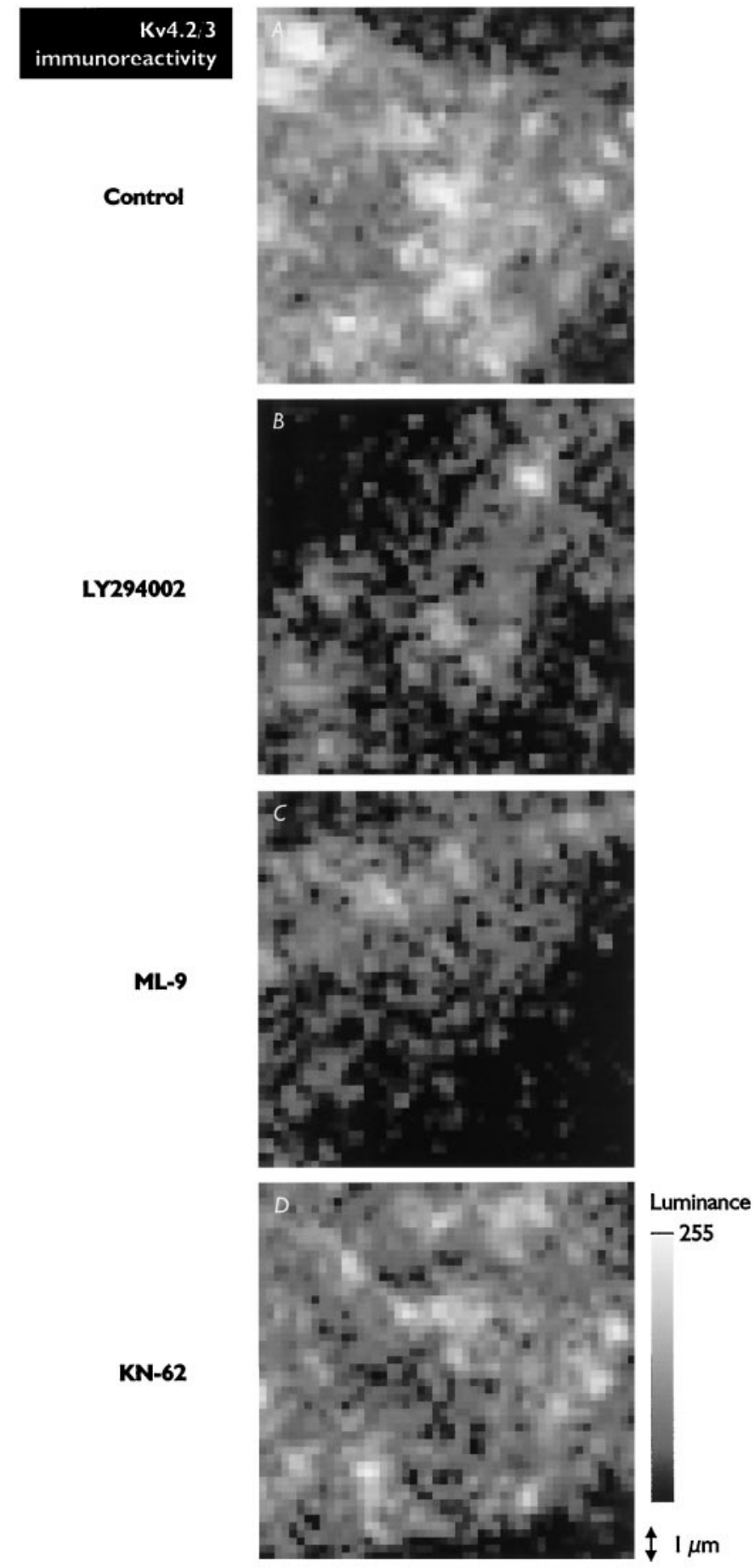

Figure 8. Enlarged portions of fluorescence images near the regions indicated by the arrows in Figure 7, illustrating punctate areas of Kv4.2/3 immunoreactivity. Individual punctata had diameters of $0.5-0.75 \mu \mathrm{m}$, because each pixel represents $\sim 0.2 \times 0.2 \mu \mathrm{m}$ in the image plane. In neurons exposed to $L Y 294002(B), M L-9(C)$, or $K N-62(D)$, the maximum luminance of individual punctata was comparable to that of control neurons $(A)$, as indicated by the luminance scale; only punctata densities and distributions appeared to be affected by the kinase inhibitors.

exposed to inhibitors. Diameters of these punctata and their maximum luminance were similar to values seen in control neurons (Fig. 8C).

Inhibition of $\mathrm{Ca}^{2+}$-calmodulin-dependent protein kinase II by
$K N$-62. Multiple lines of investigation point to a role for CaMKII in control of exocytosis (see Discussion). We used the CaMKII inhibitor KN-62 (Tokumitsu et al., 1990).

Electrophysiological measurements indicated that growth in the presence of KN-62 $(10 \mu \mathrm{M})$ reduced whole-cell capacitance to $65 \%$ of control (Fig. $4 C$ ) and reduced $I_{\mathrm{A}}$ amplitude to $60 \%$ of control, $I_{\mathrm{D}}$ amplitude to $60 \%$ of control, and $I_{\mathrm{K}}$ amplitude to $52 \%$ of control (Fig. $5 C$ ). However, neither $I_{\mathrm{A}}, I_{\mathrm{D}}$, nor $I_{\mathrm{K}}$ densities were affected (Fig. $6 C$ ), despite the clear reduction in membrane area.

Images of Kv4.2/3 immunoreactivity (Fig. 7D3,4) showed a slight reduction in overall luminance as compared with control neurons (Fig. 7A3,4), but no change in its almost uniform distribution. As was true for the other inhibitors, this appeared to be attributable to a reduction in the density of Kv4.2/3immunoreactive punctata rather than to decreases in their diameter or maximum luminance (Fig. 8D).

Inhibition of protein kinase $C$ by calphostin $C$, bisindolymaleimide $I$, or $K-252 b$. We explored the role of PKC in regulation of potassium current development using the inhibitors calphostin $\mathrm{C}$ (Kobayashi et al., 1989; Tamaoki, 1991), K-252b (Kase et al., 1987), and bisindolymaleimide I (and its inactive variant bisindolymaleimide V; Toullec et al., 1991).

Electrophysiological measurements indicated that neurons grown in the presence of bisindolymaleimide I (data not shown), calphostin C (Figs. 4D, 5D, 6D), or K-252b (Fig. 10) displayed patterns of total cell capacitance and potassium current development that were similar to those of control neurons. This was in contrast to the clear effects of K-252a (see below), a structural relative of K-252b.

\section{Broad spectrum kinase inhibitors}

These experiments used two compounds, staurosporine and K-252a, that inhibit a broad spectrum of kinases (Tamaoki, 1991) and illustrate two additional points.

First, experiments with staurosporine indicated that growth in serum-free medium could mimic the effects of astroglial contact, in that membrane expansion and potassium current development showed the same sensitivity to kinase inhibition. Comparison of results obtained with $20 \mathrm{~nm}$ staurosporine show that neurons exposed in serum-containing medium had reduced total cell capacitance ( $72 \%$ of control), $I_{\mathrm{A}}$ amplitude (33\% of control), and $I_{\mathrm{A}}$ density (41\% of control), but essentially unaffected $I_{\mathrm{D}}$ or $I_{\mathrm{K}}$ (Fig. $9 A)$, whereas neurons exposed in serum-free medium (Neurobasal-B-27) also had reduced total cell capacitance $(56 \%$ of control), $I_{\mathrm{A}}$ amplitude (20\% of control), and $I_{\mathrm{A}}$ density (36\% of control) but essentially unaffected $I_{\mathrm{D}}$ and $I_{\mathrm{K}}$ (Fig. $9 B$ ).

Second, comparison of results obtained with K-252a and $\mathrm{K}-252 \mathrm{~b}$ confirms the general pattern of kinase sensitivities observed above. K-252a affects multiple protein kinases including PKC, cyclic nucleotide-dependent protein kinases, CaMKII, and protein tyrosine kinase, whereas $\mathrm{K}-252 \mathrm{~b}$ is more selective for PKC (Lazarovici et al., 1996). As illustrated in Figure 10, exposure to K-252a reduced whole-cell capacitance to $56 \%$ of control, $I_{\mathrm{A}}$ amplitude to $41 \%$ of control, $I_{\mathrm{D}}$ amplitude to $61 \%$ of control, and $I_{\mathrm{K}}$ amplitude to $37 \%$ of control, while reducing $I_{\mathrm{A}}$ density to $51 \%$ of control, not affecting $I_{\mathrm{D}}$ density, and reducing $I_{\mathrm{K}}$ density to $45 \%$ of control. In parallel cultures, exposure to K-252b did not affect total cell capacitance or development of potassium currents. 
A

Staurosporine

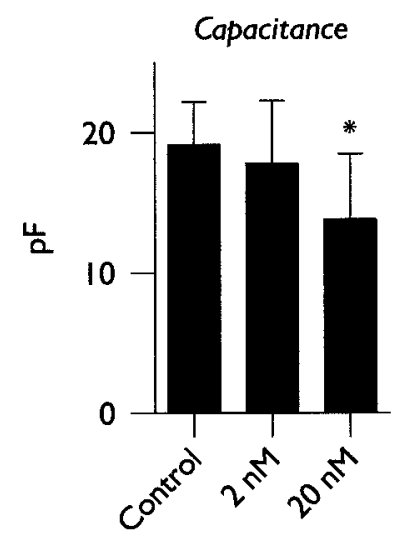

B

\section{Staurosporine}

(Neurobasal/B-27)

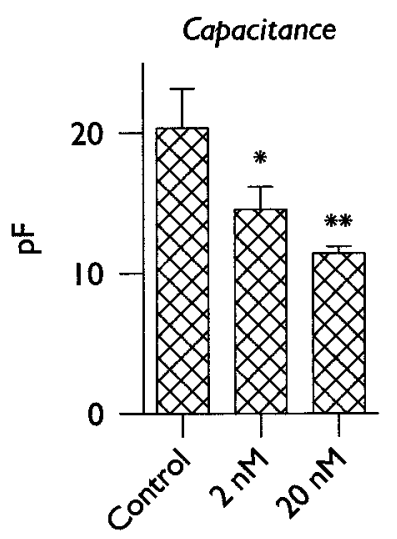

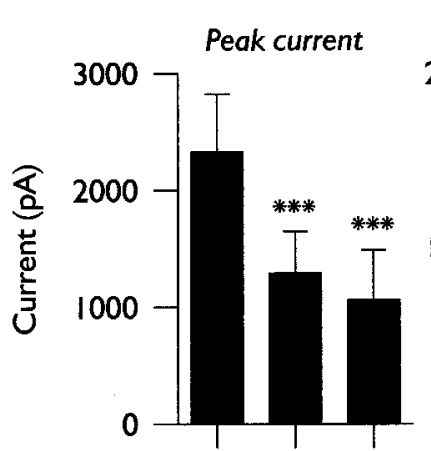
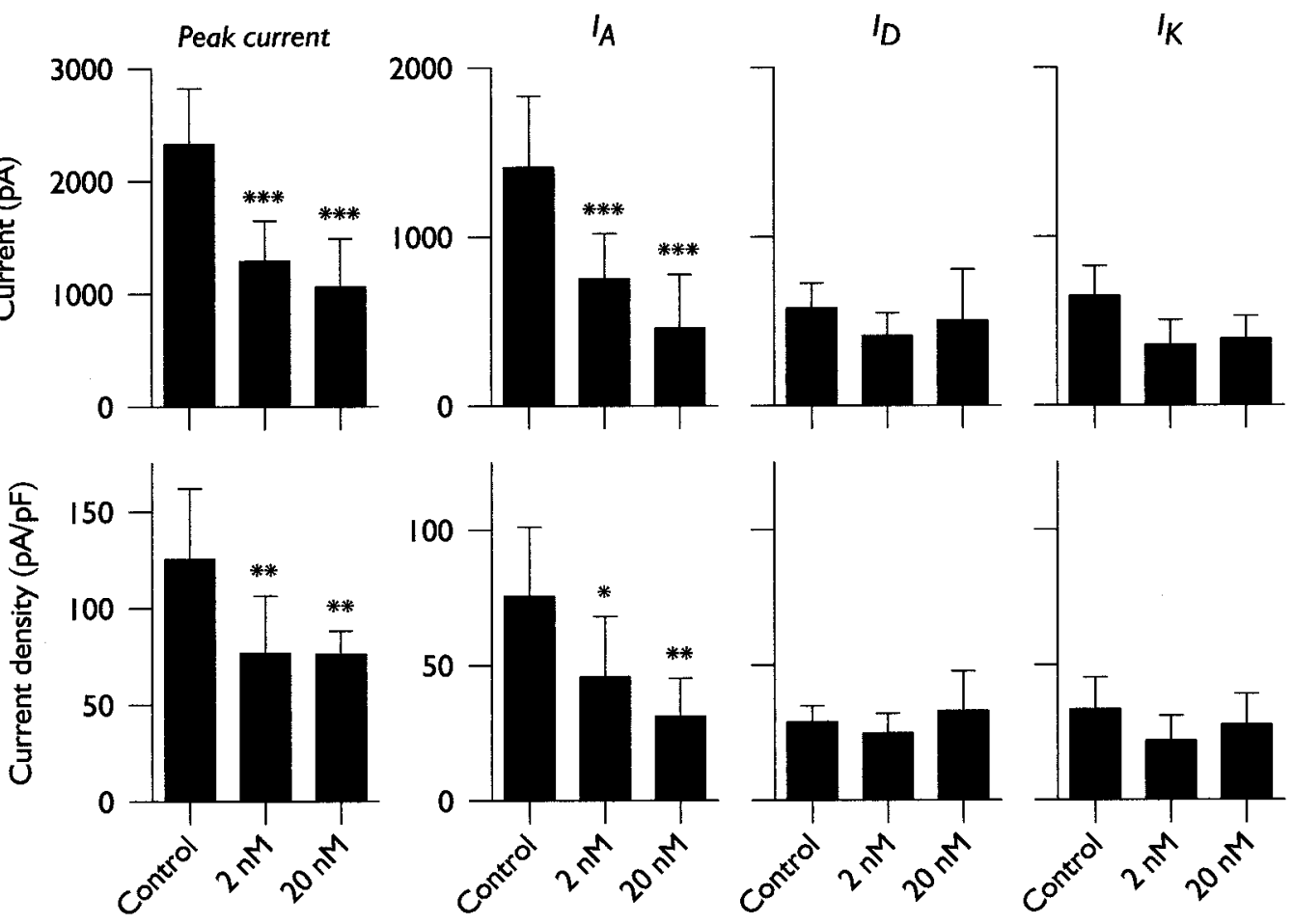

$I_{A}$
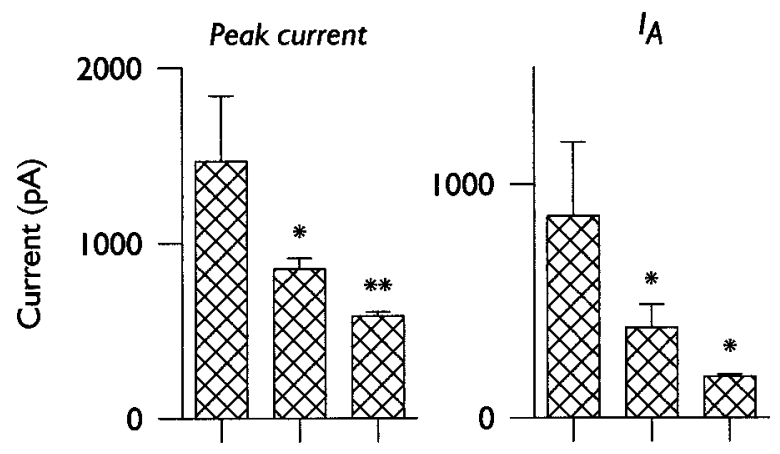

$I_{D}$

$I_{K}$
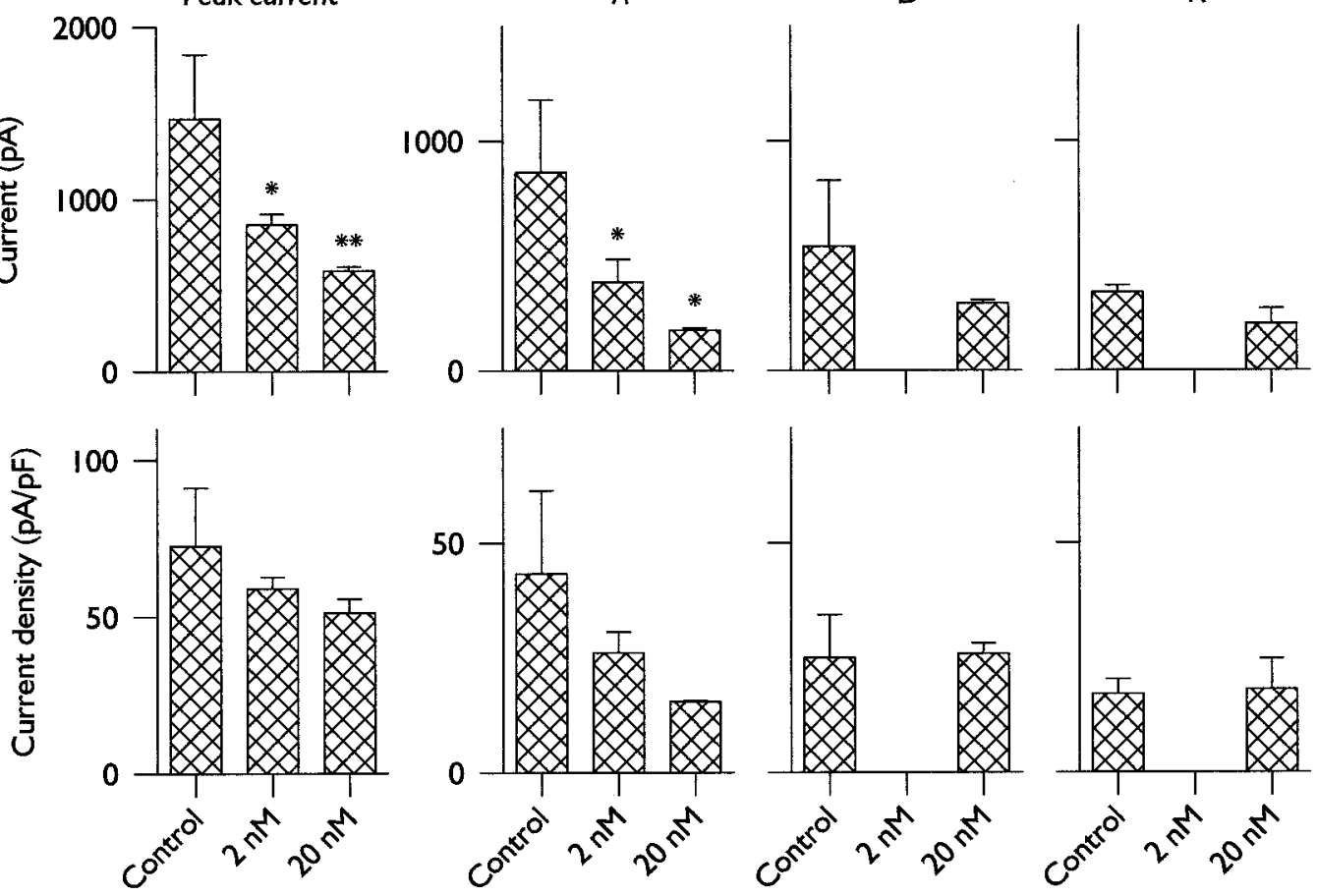

Figure 9. Effects of growth in the presence of staurosporine on total cell capacitance and potassium current development when neurons were grown in normal (low serum) medium $(A)$, or serum-free Neurobasal-B-27 medium $(B)$. Comparable results were obtained under both conditions, a result indicating that neither serum nor astroglial contact were required for kinase-sensitive control of $I_{\mathrm{A}}$ development. $A$, Numbers of cells: 7 Control, 14 $2 \mathrm{nM}$, and $720 \mathrm{nM}$. B, Numbers of cells: 4 Control, $42 \mathrm{nM}$, and $220 \mathrm{nM}$ (neurons exposed to staurosporine in Neurobasal-B-27 medium were extremely fragile, and recordings sufficiently stable for acquisition of all data were difficult to maintain). 


\section{DISCUSSION}

\section{Regulation of electrogenesis}

A major implication of these experiments is that growth of particular neuronal regions may be driving targeted insertion of specific ion channels. Thus, whereas some channels may be uniformly distributed over the neuronal surface, membrane expansion may also result in selective insertion of particular channels to create a mosaic of channel types over the neuronal surface.

For developing hippocampal neurons, PI 3-kinases may be critical elements of signaling pathways regulating both A-type potassium channel synthesis and fusion of channel-bearing vesicles into regions of expanding membrane. The late embryonic and early postnatal period examined here (corresponding to the first 7-10 d in culture) is characterized by the initial preferential development of $I_{\mathrm{A}}$ (Ficker and Heinemann, 1992; Wu and Barish, 1992; Spigelman et al., 1992), and this process was disrupted by exposure of neurons growing in contact with astroglial cells to inhibitors of PI 3-kinases.

Further, dendritic growth may occur by insertion of membrane specifically enriched in A-type potassium channels. Localization of both $I_{\mathrm{A}}$ (Spigelman et al., 1992; Hoffman et al., 1997) and Kv4.2/3 immunoreactivity (Sheng et al., 1992; Maletic-Savatic et al., 1995b; Tsaur et al., 1997; this report) to somata and dendrites suggests the presence of a population of targeted vesicles bearing A-type potassium channels. These vesicles may be the Kv4.2/3immunoreactive punctata illustrated (Figs. 7, 8), because their density was reduced by exposure to LY294002, and they were similar in appearance to the mobile tubulovesicular transport vesicles recently described by Nakata et al. (1998). However, we have not yet compared the distributions of Kv4.2/3immunoreactive structures to markers of compartments of the secretory pathway (Krijnse-Locker et al., 1995), or determined if LY294002 perturbs generation of all transport vesicles, the presence of Kv4.2/3 immunoreactivity on transport vesicles, or both.

Unlike observations on $I_{\mathrm{A}}$, changes in $I_{\mathrm{D}}$ and $I_{\mathrm{K}}$ amplitudes after inhibition of PI 3-kinases were in proportion to reductions in membrane area (compare Figs. 5A1,2, 6A1,2). This suggests either (1) that minimal synthesis of the subunits comprising these channels was occurring during this period and that insertion was drawing on a preexisting subunit pool, or (2) that subunit synthesis was minimally affected by kinase inhibition. Regardless, these data also suggest regulation of channel insertion by PI 3-kinases.

\section{Role of PI 3-kinases}

How valid is our interpretation implicating PI 3-kinases in regulation of development of excitability?

First, the specificity of the inhibitors used suggests involvement of PI 3-kinases. We used unrelated membrane-permeant inhibitors of PI 3-kinases, either LY294002 or wortmannin. LY294002 was effective at the micromolar concentration for which it is selective for PI 3-kinases (Vlahos et al., 1994) over PI 4-kinases (Vlahos et al., 1994) or myosin light chain kinase (Yano et al., 1995). Unlike wortmannin, LY294002 is stable when added to cultures (Vlahos et al., 1994). Wortmannin at nanomolar concentrations is selective for PI 3-kinases (Shepherd et al., 1996), but at higher (micromolar) concentrations affects other kinases, including PI 4-kinases (Nakanishi et al., 1995) and myosin light chain kinase (Nakanishi et al., 1992). Wortmannin was used at micromolar concentrations, which appears inconsistent with actions restricted to PI 3-kinases. However, wortmannin is notoriously unstable, and in serum-containing cultures loses effectiveness after $\sim 5$ hr (Kimura et al., 1994). Because wortmannin was added to cultures at intervals of 8 and $16 \mathrm{hr}$, its concentration was almost certainly below its nominal value. Therefore, although we do not exclude the possibility that wortmannin was affecting other targets, we suggest that a major action of wortmannin was on PI 3-kinases.

Second, because the PI 3-kinases are a family of related kinases (Zvelebil et al., 1996), particular PI 3-kinases might influence hippocampal neuron development at different sites (Ward et al., 1996). PI 3-kinases appear to serve two major overlapping classes of functions. Some PI 3-kinases are activated as part of the signaling cascade initiated by protein tyrosine kinases and may regulate additional kinases potentially linked to control of transcription factor activity (Kapeller and Cantley, 1994) as well as to control of intracellular membrane trafficking (De Camilli et al., 1996; Shepherd et al., 1996). Other PI 3-kinases may directly regulate intracellular membrane trafficking (De Camilli et al., 1996; Shepherd et al., 1996).

Although no other studies have directly addressed involvement of PI 3-kinases in the development of excitability, in studies of PC12 cells, neurite growth was induced by introduction of a constitutively active PI 3-kinase and inhibited by wortmannin (Kimura et al., 1994; Kobayashi et al., 1997). Other studies in neurons have examined PI 3-kinases in relation to regulation of apoptosis (Nomomura et al., 1996; D’Mello et al., 1997; Miller et al., 1997).

\section{Relation to the association of $I_{\mathrm{A}}$ development with astroglial contact}

The similarity of the results obtained with inhibitors of PI 3-kinases to our previous observations of the effects of astroglial contact (Wu and Barish, 1994), control of $I_{\mathrm{A}}$ amplitude and density in association with changes in membrane area, suggests that PI 3-kinases may be elements of intracellular signaling pathways in neurons whose activation is linked to astroglial contact. In this model, reception of signals originating in astroglial cells would activate tyrosine kinases (possibly receptor tyrosine kinases), and subsequent activation of PI 3-kinases could regulate $I_{\mathrm{A}}$ development. Future work will be directed toward identification of the neuronal receptor(s) responding to astroglial contact and their linkages to particular PI 3-kinases.

\section{Role of myosin light chain kinase}

Our observations suggest involvement of myosin and myosin light chain kinase in regulation of vesicle populations available for exocytosis, because exposure to ML-9 reduced membrane area and potassium current amplitudes and the overall luminance of Kv4.2/3 immunoreactivity. Significantly, Kv4.2/3 immunoreactivity showed greater restriction to perinuclear portions than was evident in control neurons or in neurons exposed to the CaMKII inhibitor KN-62, suggesting inhibition of peripheral migration of Kv4.2/3 immunoreactivity. This process was not totally arrested, perhaps because cells possess multiple vesicle transport systems (Fath and Burgess, 1994). Nevertheless, our interpretation is consistent with other analyses of myosin functions (Mermall et al., 1998) because: (1) the subcellular distributions of myosins and their associations with vesicles suggest a transport function in somata (Mermall et al., 1998), and (2) functional analyses of myosins suggest involvement in vesicle transport and exocytosis (Ohara-Imaizumi et al., 1992; Kumakura et al., 1994; Mermall et al., 1994; Mochida et al., 1994; Rao et al., 1997). 
K-252a

K-252b

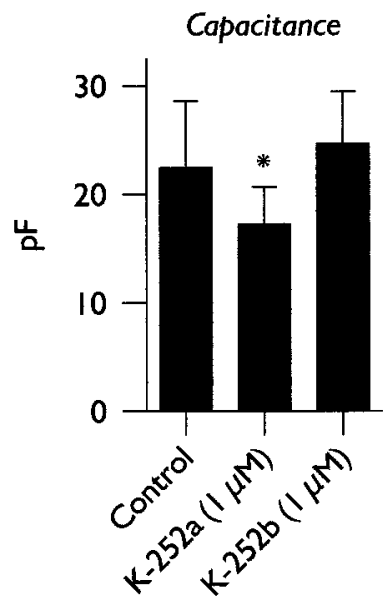

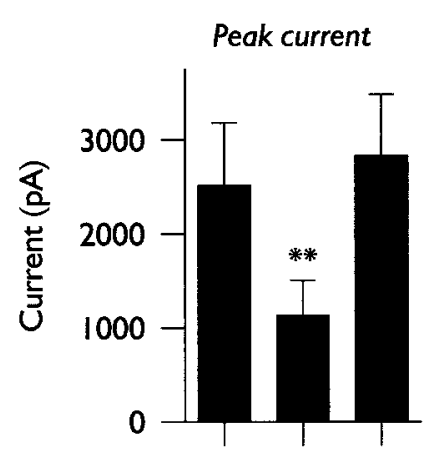
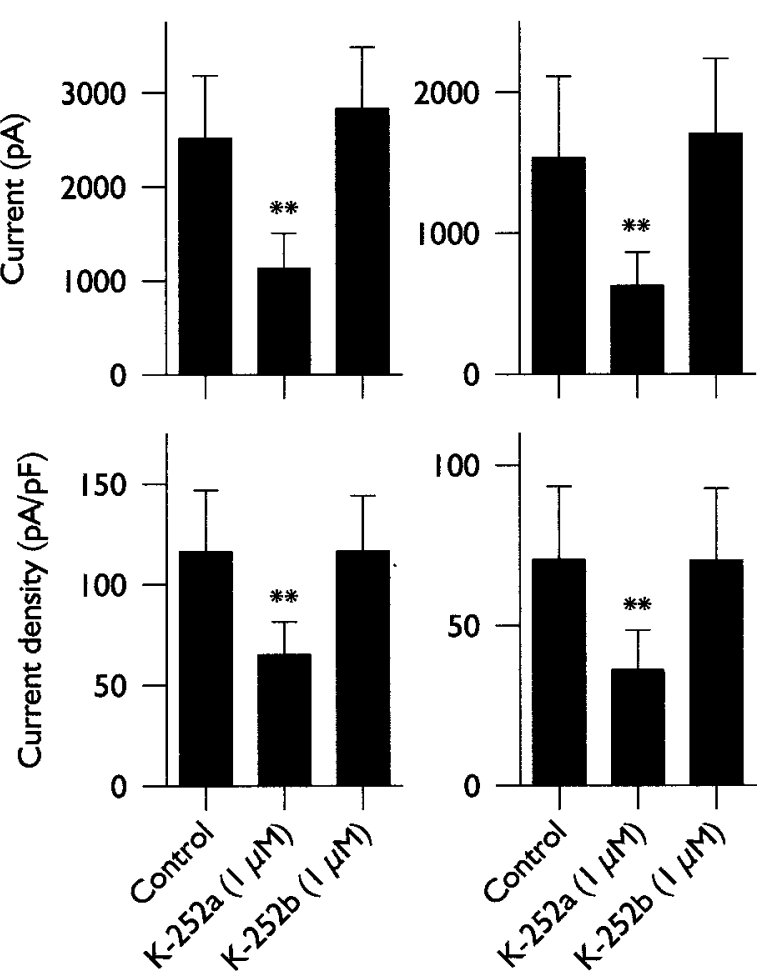

$I_{A}$

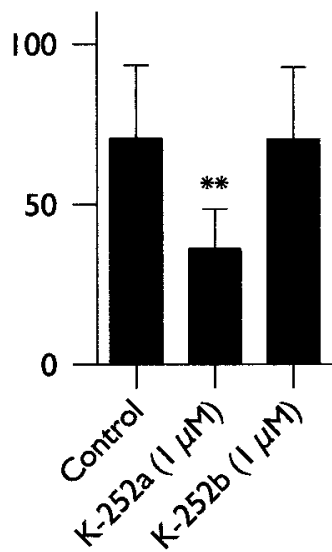

$I_{D}$

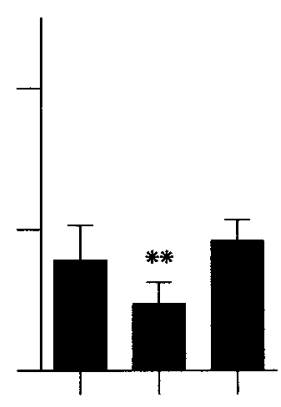

$I_{K}$
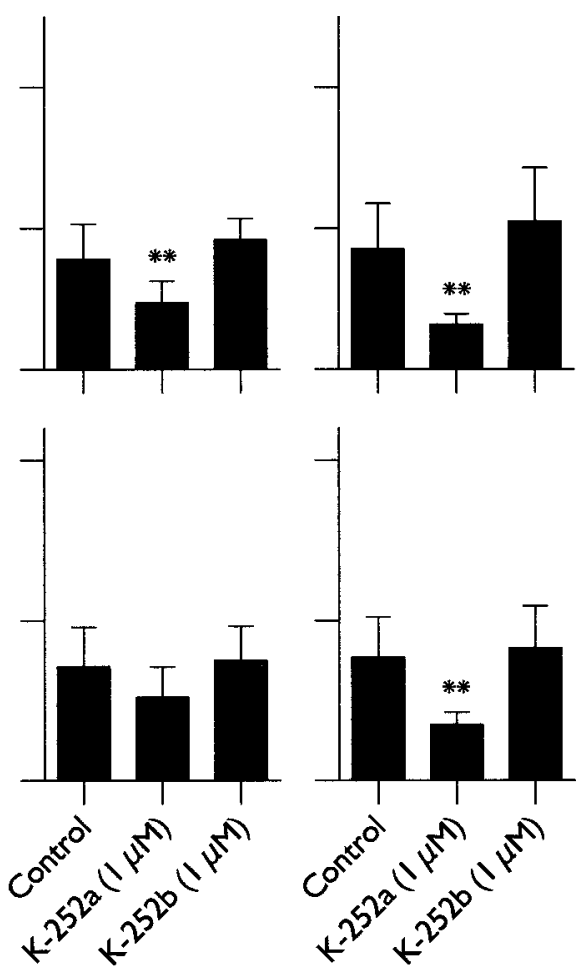

Figure 10. Effects of growth in the presence of the broad spectrum kinase inhibitor K-252a and its PKC-preferring variant K-252b on total cell capacitance and potassium current development. Exposure to K-252a affected membrane area, the amplitudes of $I_{\mathrm{A}}, I_{\mathrm{D}}$, and $I_{\mathrm{K}}$, and densities of $I_{\mathrm{A}}$ and $I_{\mathrm{K}}$. In contrast, exposure to K252b did not affect membrane area or development of any of the potassium currents. Numbers of cells: 21 control, 14 K252a, and $9 \mathrm{~K} 252 b$.

\section{Role of calcium-calmodulin-dependent protein kinase II}

Our observations also suggest that CaMKII regulates fusion of transport vesicles with the plasmalemma at a site close to the exocytotic step, because growth in the presence of a CaMKII inhibitor reduced membrane area and potassium current amplitudes proportionately without substantially affecting the intensity or distribution of Kv4.2/3 immunoreactivity. This model is consistent with recent observations of chronic CaMKII-sensitive membrane cycling at nonsynaptic as well as synaptic sites on developing hippocampal neurons (Matteoli et al., 1992; MaleticSavatic et al., 1995a, 1996).

Other studies have also reported a relationship between CaMKII activity and neuronal growth, in particular with neurite extension and branching, and growth cone motility (Cabell and Audesirk, 1993; Goshima et al., 1993; Williams et al., 1995; Audesirk et al., 1997).

Studies of neurotransmitter release indicate that CaMKII may affect exocytosis by regulating vesicle mobility and availability for docking and eventual membrane fusion (Llinás et al., 1985; Greengard et al., 1993; Ceccaldi et al., 1995; Nielander et al., 1995; Maletic-Savatic et al., 1995a, 1996). Similar mechanisms may be involved in neuronal growth regulation.

\section{Role of protein kinase $\mathbf{C}$}

Growth in the presence of PKC inhibitors did not affect membrane area (measured electrophysiologically) or potassium current development, an observation consistent with our notion that membrane expansion and potassium channel insertion are linked.
This insensitivity to PKC inhibitors was unexpected because PKC regulates a number of processes involving vesicle fusion (Strong et al., 1987; Finch and Jackson, 1990; Parfitt and Madison, 1993; Corey et al., 1994; Billiard et al., 1997). However, in a broad way our observations are consistent with studies indicating that inhibition of PKC with calphostin $\mathrm{C}$ reduced only axon branching, but not dendrite number, branching, or length (Cabell and Audesirk, 1993; Audesirk et al., 1997) because we believe A-type potassium channels incorporating Kv4.2/3 subunits to be restricted to somatic and dendritic membrane.

\section{Other studies linking membrane expansion to ion channel insertion and the potential significance of linked growth and excitability}

The first studies linking changes in excitability (hyperpolarization of developing bastomeres) with membrane expansion were experiments on dividing early amphibian embryos (Woodward, 1968; de Laat and Bluemink, 1974), which demonstrated enhanced potassium permeability in membrane newly inserted at the cleavage furrow.

More recently, several studies have examined episodes of membrane expansion linked to regulation of excitability. In Aplysia bag cell neurons, appearance of action potential-triggered $\mathrm{Ca}^{2+}$ influx at the distal edges of expanding lamellipodia (Knox et al., 1992) is attributable to PKC-regulated recruitment of "covert" calcium channels to the surface membrane (Strong et al., 1987) from a pool of vesicular calcium channels (White and Kaczmarek, 1997). In neuroblastoma cells, continuous exposure to $\omega$-conotoxin GVIA $\left(\omega\right.$-CgTX) GVIA or $\mathrm{Cd}^{2+}$ increases $I_{\mathrm{Ca}}$ and 
depolarization-induced intracellular $\mathrm{Ca}^{2+}$ transients (Passafaro et al., 1992, 1994, 1996) by processes associated with increase in the number of surface ${ }^{125} \mathrm{I}-\omega$-CgTX GVIA-binding sites and parallel loss of internal binding sites. In growth cone particles derived from fetal rat brain, externalization of voltage-gated sodium channels from intracellular reservoirs (Schmidt et al., $1985)$ is sensitive to disruption of the membrane fusion apparatus (Wood et al., 1992), as may be channels in these other examples.

More generally, the experiments presented here have significance for our understanding of nervous system assembly and signaling plasticity, because they imply that the morphological transformations that accompany both development (Harris et al., 1992; Purves et al., 1994) and use-dependent synaptic modifications (Bailey and Chen, 1989; Glanzman et al., 1990; Hosokawa et al., 1995) may be accompanied by changes in channel or receptor numbers and distributions. A specific suggestion is the possibility of "silent" glutamate receptors potentially exposed at central synapses during the development and/or expression phases of hippocampal long-term synaptic potentiation (Isaac et al., 1995; Liao et al., 1995; Durand et al., 1996; Wu et al., 1996). A critical issue is thus elucidation of the rules governing specific forms of membrane expansion and linkages to particular ion channel and neurotransmitter receptor subunits.

\section{REFERENCES}

Audesirk G, Cablee L, Kern M (1997) Modulation of neurite branching by protein phosphorylation in cultured rat hippocampal neurons. Dev Brain Res 102:247-260.

Bailey CH, Chen M (1989) Time course of structural changes at identified sensory neuron synapses during long-term sensitization in Aplysia. J Neurosci 9:1774-1780.

Banker GA, Cowan WM (1977) Rat hippocampal neurons in dispersed cell culture. Brain Res 126:397-425.

Banker GA, Cowan WM (1979) Further observations on hippocampal neurons in dispersed cell culture. J Comp Neurol 187:469-494.

Barish ME (1995) Modulation of the electrical differentiation of neurons by interactions with glia and other non-neuronal cells. Perspect Dev Neurobiol 2:357-370.

Barry DM, Trimmer JS, Merlie JP, Nerbonne JM (1995) Differential expression of voltage-gated $\mathrm{K}^{+}$channel subunits in adult rat heart. Circ Res 77:361-369.

Bartlett WP, Banker GA (1984a) An electron microscopic study of the development of axons and dendrites by hippocampal neurons in culture. I. Cells which develop without intercellular contacts. J Neurosci 4:1944-1953.

Bartlett WP, Banker GA (1984b) An electron microscopic study of the development of axons and dendrites by hippocampal neurons in culture. II. Synaptic relationships. J Neurosci 4:1954-1965.

Berghorn KA, Bonnett JH, Hoffman GE (1994) cFos immunoreactivity is enhanced with biotin amplification. J Histochem Cytochem 42:1635-1642.

Billiard J, Koh D-S, Babcock DF, Hille B (1997) Protein kinase C as a signal for exocytosis. Proc Natl Acad Sci USA 94:12192-12197.

Brewer GJ (1995) Serum-free B27/Neurobasal medium supports differentiated growth of neurons from the striatum, substantia nigra, septum, cerebral cortex, cerebellum, and dentate gyrus. J Neurosci Res 42:674-683.

Brewer GJ, Torricelli JR, Evege EK, Price PJ (1993) Optimized survival of hippocampal neurons in B27-supplemented Neurobasal, a new serum-free medium combination. J Neurosci Res 35:567-576.

Cabell L, Audesirk G (1993) Effects of elective inhibition of protein kinase $\mathrm{C}$, cyclic amp-dependent protein kinase, and $\mathrm{Ca}^{2+}$-calmodulindependent protein kinase on neurite development in cultured rat hippocampal neurons. Int J Dev Neurosci 11:357-368.

Caceres A, Banker G, Steward O, Binder L, Payne M (1984) MAP2 is localized to the dendrites of hippocampal neurons which develop in culture. Dev Brain Res 13:314-318.

Ceccaldi P-E, Grohovaz F, Benfenati F, Chieregatti E, Greengard P, Valtorta F (1995) Dephosphorylated synapsin I anchors synaptic ves- icles to actin cytoskeleton: an analysis by videomicroscopy. J Cell Biol 128:905-912.

Connor JA, Stevens CF (1971a) Voltage clamp studies of a transient outward current in gastropod neural somata. J Physiol (Lond) 213:21-30.

Connor JA, Stevens CF (1971b) Prediction of repetitive firing behaviour from voltage clamp data on an isolated neurone soma. J Physiol (Lond) 213:31-53.

Corey JL, Davidson N, Lester HA, Brecha N, Quick MW (1994) Protein kinase $\mathrm{C}$ modulates the activity of a cloned $\gamma$-aminobutyric acid transporter expressed in Xenopus oocytes via regulated subcellular redistribution of the transporter. J Biol Chem 269:14759-14767.

De Camilli P, Emr SD, McPherson PS, Novick P (1996) Phosophoinositides as regulators in membrane traffic. Science 271:1533-1539.

de Laat SW, Bluemink JG (1974) New membrane formation during cytokinesis in normal and cytochalasin B-treated eggs of Xenopus laevis. II. Electrophysiological observations. J Cell Biol 60:529-540.

D'Mello SR, Borodezt K, Soltoff SP (1997) Insulin-like growth factor and potassium depolarization maintain neuronal survival by distinct pathways: possible involvement of PI 3-kinase in IGF-1 signaling. J Neurosci 17:1548-1560.

Dotti CG, Sullivan CA, Banker GA (1988) The establishment of polarity by hippocampal neurons in culture. J Neurosci 8:1454-1468.

Durand GM, Kovalchuk Y, Konnerth A (1996) Long-term potentiation and functional synapse induction in developing hippocampus. Nature 381:71-75.

Fallon JR (1985) Preferential outgrowth of central nervous system neurites on astrocytes and Schwann cells as compared with non-glial cells in vitro. J Cell Biol 100:198-207.

Fath KR, Burgess DR (1994) Membrane motility mediated by unconventional myosin. Curr Opin Cell Biol 6:131-135.

Ficker E, Heinemann U (1992) Slow and fast transient potassium currents in cultured rat hippocampal cells. J Physiol (Lond) 445:431-455.

Finch DM, Jackson MB (1990) Presynaptic enhancement of synaptic transmission in hippocampal cell cultures by phorbol esters. Brain Res 518:269-273.

Glanzman DL, Kandel ER, Schacher S (1990) Target-dependent structural changes accompanying long-term synaptic facilitation in Aplysia neurons. Science 249:799-802.

Goshima Y, Ohsako S, Yamauchi T (1993) Overexpression of $\mathrm{Ca}^{2+} /$ calmodulin-dependent protein kinase II in Neuro2a and NG108-15 neuroblastoma cell lines promotes neurite outgrowth and growth cone motility. J Neurosci 13:559-567.

Greengard P, Valtorta F, Czernik AJ, Benfenati F (1993) Synaptic vesicle phosphoproteins and regulation of synaptic function. Science 259:780-785.

Harris KM, Jensen FE, Tsao B (1992) Three-dimensional structure of dendritic spines and synapses in rat hippocampus at postnatal day 15 and adult ages: implications for the maturation of synaptic physiology and long-term potentiation. J Neurosci 12:2685-2705.

Hoffman DA, Magee JC, Colbert CM, Johnston D (1997) $\mathrm{K}^{+}$channel regulation of signal propagation in dendrites of hippocampal pyramidal neurons. Nature 387:869-875.

Hosokawa T, Rusakov DA, Bliss TV, Fine A (1995) Repeated confocal imaging of individual dendritic spines in the living hippocampal slice: evidence for changes in length and orientation associated with chemically induced LTP. J Neurosci 15:5560-5573.

Isaac JTR, Nicoll RA, Malenka RC (1995) Evidence for silent synapses: implications for the expression of LTP. Neuron 15:427-434.

Johns DC, Nuss HB, Marban E (1997) Suppression of neuronal and cardiac transient outward currents by viral gene transfer of dominantnegative Kv4.2 constructs. J Biol Chem 272:31598-31603.

Johnston D, Brown TH (1984) Biophysics and microphysiology of synaptic transmission in hippocampus. In: Brain slices (Dingledine R, ed), pp 51-86. New York: Plenum.

Kapeller R, Cantley LC (1994) Phosphatidyl 3-kinase. Bioessays $16: 565-576$

Kase H, Iwahashi K, Nakanishi S, Matsuda Y, Yamada K, Takahashi M, Murakata C, Sato A, Kaneko M (1987) K-252 compounds, novel and potent inhibitors of protein kinase $\mathrm{C}$ and cyclic nucleotide-dependent protein kinases. Biochem Biophys Res Commun 142:436-440.

Keros S, McBain CJ (1997) Arachidonic acid inhibits transient potassium currents and broadens action potentials during electrographic seizures in hippocampal pyramidal and inhibitory interneurons. J Neurosci 17:3476-3487. 
Kimura K, Hattori S, Kauyama Y, Shizawa Y, Takayanagi J, Nakamura S, Toki S, Matsuda Y, Onodera K, Fukui Y (1994) Neurite outgrowth of PC12 cells is suppressed by wortmannin, a specific inhibitor of phosphatidylinositol 3-kinase. J Biol Chem 269:18961-18967.

Knox RJ, Quattrocki EA, Connor JA, Kaczmarek LK (1992) Recruitment of $\mathrm{Ca}^{2+}$ channels by protein kinase $\mathrm{C}$ during rapid formation of putative neuropeptide release sites in isolated Aplysia neurons. Neuron 8:883-889.

Kobayashi E, Nakano H, Morimoto M, Tamaoki T (1989) Calphostin C (UCN-1028C), a novel microbial compound, is a highly potent and specific inhibitor of protein kinase C. Biochem Biophys Res Commun 159:548-553

Kobayashi M, Nagata S, Kita Y, Nakatsu N, Ihara S, Kaibuchi K, Kuroda S, Ui M, Iba H, Konishi H, Kikkawa U, Saitoh I, Fukui Y (1997) Expression of constitutively active phosphatidylinositol 3-kinase induces process formation in rat $\mathrm{PC} 12$ cells. Use of Cre/loxP recombination system. J Biol Chem 272:16089-16092.

Kriegstein AR, Dichter MA (1983) Morphological classification of rat cortical neurons in cell culture. J Neurosci 3:1634-1647.

Krijnse-Locker J, Parton RG, Fuller SD, Griffiths G, Dotti CG (1995) The organization of the endoplasmic reticulum and the intermediate compartment in cultured rat hippocampal neurons. Mol Biol Cell 6:1315-1332.

Kumakura K, Sasaki K, Sakurai T, Ohara-Imaizumi M, Misonou H, Nakamura S, Matsuda Y, Nonomura Y (1994) Essential role of myosin light chain kinase in the mechanism for MgATP-dependent priming of exocytosis in adrenal chromaffin cells. J Neurosci 14:7695-7703.

Lazarovici P, Rasouly D, Friedman L, Tabekman R, Ovadia H, Matsuda Y (1996) $\mathrm{K}_{252 \mathrm{a}}$ and staurosporine microbial alkaloid toxins as prototype of neurotropic drugs. Adv Exp Med Biol 391:367-77.

Liao D, Hessler NA, Malinow R (1995) Activation of postsynaptically silent synapses during pairing-induced LTP in CA1 region of hippocampal slice. Nature 375:400-404.

Llinás R, McGuinness TL, Leonard CS, Sugimori M, Greengard P (1985) Intraterminal injection of synapsin I or calcium/calmodulindependent protein kinase II alters neurotransmitter release at the squid giant synapse. Proc Natl Acad Sci USA 82:3035-3039.

Maletic-Savatic MM, Koothan T, Malinow R (1995a) Dendritic calciumdependent exocytosis in cultured hippocampal neurons: role of calcium/calmodulin protein kinase II. Soc Neurosci Abstr 21:1743.

Maletic-Savatic MM, Lenn NJ, Trimmer JS (1995b) Differential spatiotemporal expression of $\mathrm{K}^{+}$channel polypeptides in rat hippocampal neurons developing in situ and in vitro. J Neurosci 15:3840-3851.

Maletic-Savatic M, Koothan T, Malinow R (1996) CaMKII action on microtubules promotes calcium-evoked dendritic exocytosis. Soc Neurosci Abstr 22:515.

Matteoli M, Takei K, Perin MS, Südhof TC, De Camilli P (1992) Exoendocytotic recycling of synaptic vesicles in developing processes of cultured hippocampal neurons. J Cell Biol 117:849-861.

Mermall V, McNally JG, Miller KG (1994) Transport of cytoplasmic particles catalysed by an unconventional myosin in living Drosophila embryos. Nature 369:560-562.

Mermall V, Post PL, Mooseker MS (1998) Unconventional myosins in cell movement, membrane traffic, and signal transduction. Science 279:527-533.

Miller TM, Tansey MG, Johnson Jr EM, Creedon DJ (1997) Inhibition of phosphatidylinositol 3-kinase activity blocks depolarization- and insulin-like growth factor I-mediated survival of cerebellar granule cells. J Biol Chem 272:9847-9853.

Mochida S, Nonomura Y, Kobayshi H (1994) Analysis of the mechanism for acetylcholine release at the synapse formed between rat sympathetic neurons in culture. Microsc Res Tech 29:94-102.

Nakanishi S, Kakita S, Takahashi I, Kawahara K, Tsukuda E, Sano T, Yamada K, Yoshida M, Kase H, Matsuda Y, Hashimoto Y, Nomomura Y (1992) Wortmannin, a microbial product inhibitor of myosin light chain kinase. J Biol Chem 267:2157-2163.

Nakanishi S, Catt KJ, Balla T (1995) A wortmannin-sensitive phosphatidylinositol 4-kinase that regulated hormone-sensitive pools of inositolphospholipids. Proc Natl Acad Sci USA 92:5317-5321.

Nakata T, Terada S, Hirokawa N (1998) Visualization of the dynamics of synaptic vesicle and plasma membrane proteins in living axons. J Cell Biol 140:659-674.

Nielander HB, Onofri F, Valtorta F, Schiavo G, Montecucco C, Greengard P, Benfenati F (1995) Phosphorylation of VAMP/Synaptobrevin in synaptic vesicles by endogenous protein kinases. J Neurochem 65:1712-1720.

Noble M, Fok-Seang J, Cohen J (1984) Glia are a unique substrate for the in vitro growth of central nervous system neurons. J Neurosci 4:1892-1903.

Nonomura T, Kubo T, Oka T, Shimoke K, Yamada M, Enokido Y, Hatanaka H (1996) Signaling pathways and survival effects of BDNF and NT-3 on cultured cerebellar granule cells. Dev Brain Res 97:42-50.

Ohara-Imaizumi M, Sakurai T, Nakamura S, Nakanishi S, Matsuda Y, Muramatsu S, Nonomura Y, Kumakura K (1992) Inhibition of $\mathrm{Ca}(2+)$-dependent catecholamine release by myosin light chain kinase inhibitor, wortmannin, in adrenal chromaffin cells. Biochem Biophys Res Commun 185:1016-1021.

Parfitt KD, Madison DV (1993) Phorbol esters enhance synaptic transmission by a presynaptic, calcium-dependent mechanism in rat hippocampus. J Physiol (Lond) 471:245-268.

Passafaro M, Clementi F, Sher E (1992) Metabolism of $\omega$-conotoxinsensitive voltage-operated calcium channels in human neuroblastoma cells: modulation by cell differentiation and anti-channel antibodies. J Neurosci 12:3372-3379.

Passafaro M, Clementi F, Pollo A, Carbone E, Sher E (1994) $\omega$-Conotoxin and $\mathrm{Cd}^{2+}$ stimulate the recruitment to the plasma membrane of an intracellular pool of voltage-operated $\mathrm{Ca}^{2+}$ channels. Neuron 12:317-326.

Passafaro M, Rosa P, Sala C, Clementi F, Sher E (1996) N-type Ca ${ }^{2+}$ channels are present in secretory granules and are transiently translocated to the plasma membrane during regulated exocytosis. J Biol Chem 271:30096-30104.

Pixley SKR, Nieto-Sampedro M, Cotman CW (1987) Preferential adhesion of brain astrocytes to laminin and central neurons to astrocytes. J Neurosci Res 18:402-406.

Purves D, Riddle DR, White LE, Guiterrez-Ospina G (1994) Neural activity and the development of the somatic sensory system. Curr Opin Neurobiol 4:120-123.

Rao K, Paik W-Y, Zheng L, Jobin RM, Tomi M, Jiang H, Nakanishi S, Stojilkovic SS (1997) Wortmannin-sensitive and -insensitive steps in calcium-controlled exocytosis in pituitary gonadotrophs: evidence that myosin light chain kinase mediates calcium-dependent and wortmannin-sensitive gonadotropin secretion. Endocrinology 138: $1440-1449$

Saitoh M, Naka M, Hidaka H (1986) The modulatory role of myosin light chain phosphorylation in human platelet activation. Biochem Biophys Res Commun 140:280-287.

Schmidt J, Rossie S, Catterall WA (1985) A large intracellular pool of inactive $\mathrm{Na}$ channel $\alpha$ subunits in developing rat brain. $\mathrm{J}$ Neurosci 82:4847-4851.

Serôdio P, Kentros C, Rudy B (1994) Identification of molecular components of A-type channels activating at subthreshold potentials. J Neurophysiol 72:1516-1529.

Serôdio P, Vega-Saenz de Miera E, Rudy B (1996) Cloning of a novel component of A-type $\mathrm{K}^{+}$channels operating at subthreshold potentials with unique expression in heart and brain. J Neurophysiol 75:2174-2179.

Sheng M, Tsaur M-L, Jan YN, Jan LY (1992) Subcellular segregation of two A-type $\mathrm{K}^{+}$channel proteins in rat central neurons. Neuron 9:271-284.

Shepherd PR, Reaves BJ, Davidson HW (1996) Phosphoinositide 3-kinases and membrane traffic. Trends Cell Biol 6:92-97.

Spigelman I, Zhang L, Carlen PL (1992) Patch-clamp study of postnatal development of CA1 neurons in rat hippocampal slices: membrane excitability and $\mathrm{K}^{+}$currents. J Neurophysiol 68:55-69.

Storm JF (1990) Potassium currents in hippocampal pyramidal cells. Prog Brain Res 83:161-187.

Strong JA, Fox AP, Tsien RW, Kaczmarek LK (1987) Stimulation of protein kinase C recruits covert calcium channels in Aplysia bag cell neurons. Nature 325:714-717.

Tamaoki T (1991) Use and specificity of staurosporine, UCN-01, and calphostin $\mathrm{C}$ as protein kinase inhibitors. Methods Enzymol 201:340-347.

Toullec D, Pianetti P, Coste H, Bellevergue P, Grand-Perret T, Ajakane M, Baudet V, Boissin P, Boursier E, Loriolle F, et al (1991) The bisindolylmaleimide GF $109203 \mathrm{X}$ is a potent and selective inhibitor of protein kinase C. J Biol Chem 266:15771-15781.

Tokumitsu H, Chijiwa T, Hagiwara M, Mizutani A, Terasawa M, Hidaka $\mathrm{H}$ (1990) KN-62, 1 -[ $N, O$-Bis(5-isoquinolinesulfonyl)- $N$-methyl-L- 
tyrosyl]-4-phenylpiperazine, a specific inhibitor of $\mathrm{Ca}^{2+} /$ calmodulindependent protein kinase II. J Biol Chem 265:4315-4320.

Tsaur M-L, Chou C-C, Shih Y-H, Wang H-L (1997) Cloning, expression and CNS distribution of $\mathrm{Kv} 4.3$, an A-type $\mathrm{K}^{+}$channel $\alpha$ subunit. FEBS Lett 400:215-220.

Vlahos CJ, Matter WF, Hui KY, Brown RF (1994) A specific inhibitor of phosphatidylinositol 3-kinase, 2-(4-morpholinyl)-8-phenyl-4H-1benzopyran-4-one (LY294002). J Biol Chem 269:5241-5248.

Ward SG, June CH, Olive D (1996) PI 3-kinase: a pivotal pathway in T-cell activation? Immunol Today 17: 187-197.

White BH, Kaczmarek LK (1997) Identification of a vesicular pool of calcium channels in the bag cell neurons of Aplysia californica. J Neurosci 17:1582-1595.

Williams EJ, Mittal B, Walsh FS, Doherty P (1995) $\mathrm{A} \mathrm{Ca}^{2+} /$ calmodulin kinase inhibitor, $\mathrm{KN}-62$, inhibits neurite outgrowth stimulated by CAMs and FGF. Mol Cell Neurosci 6:69-79.

Wood MR, DeBin J, Strichartz GR, Pfenninger KH (1992) Plasmalemmal insertion and modification of sodium channels at the nerve growth cone. J Neurosci 12:2948-2959.

Woodward DJ (1968) Electrical signs of new membrane production during cleavage of Rana pipiens eggs. J Gen Physiol 52:509-531.
Wu G, Malinow R, Cline HT (1996) Maturation of a central glutamatergic synapse. Science 274:972-976.

Wu R-L, Barish ME (1992) Two pharmacologically and kinetically distinct transient potassium currents in cultured mouse hippocampal neurons. J Neurosci 12:2235-2246.

Wu R-L, Barish ME (1994) Astroglial modulation of transient potassium current development in cultured mouse hippocampal neurons. J Neurosci 14:1677-1687.

Wu R-L, Barish ME (1996) A-current development in hippocampal neurons: links to kinase activity and membrane insertion. Soc Neurosci Abstr 22:1250.

Yano H, Agatsuma T, Nakanishi S, Saitoh Y, Fukui Y, Nomomura Y, Matsuda Y (1995) Biochemical and pharmacological studies with KT7692 and LY294002 on the role of phosphatidylinositol 3-kinase in FceRI-mediated signal transduction. Biochem J 312:145-150.

Zvelebil MJ, MacDougall L, Leevers S, Volina S, Vanhaesebroeck B, Gout I, Panayotou G, Domin J, Stein R, Pages F, Koga H, Salim K, Linacre J, Das P, Panaretou C, Wetzker R, Waterfield M (1996) Structural and functional diversity of phosphoinositide 3-kinases. Philos Trans R Soc Lond B Biol Sci 351:217-223. 